\title{
LASST DIE KNOCHEN SPRECHEN! KNOCHEN-, GEWEIH- UND ZAHNARTEFAKTE DER VEKERZUG-KULTUR ${ }^{1}$
}

\author{
Anita Kozubová
}

DOI: https://doi.org/10.31577/szausav.2020.67.3

Keywords: Vekerzug culture, Hallstatt and Early La Tène periods, East Hungary, South Slovakia, antler, animal bones and teeth, analysis of finds, cemeteries and settlements

Let the bones speak! Bone, antler and tooth artifacts of the Vekerzug culture

In the present study, we deal with relatively numerous bone, antler and tooth artifacts of the Vekerzug culture, which come mainly from graves. Their settlement findings are yet less frequent because of limited state of publishing. Providing a more complex overview of these finds was at the centre of our interest, focused mainly on their cultural-spatial analysis, identifying the possible function of some types of artifacts and the analysis of decorative motifs on some bone/ antler objects. In the Vekerzug culture, bone and antler artifacts are typological though less varied, but some of them like decorated hollow cylindrical objects, iron knives with a zoomorphic and/or geometric ornaments on the bone/antler grip and two-piece razors are its typical feature. Some types of weapons and their parts, horse harnesses, tools and toilet instruments were made of bone and antler. Pieces of bone and animal teeth were sometimes used for personal adornments. In the Vekerzug culture, the occurrence of some types of bone/antler artifacts we can associate with the influences from the eastern Hallstatt cultural milieu, while the eastern relations are rarely observed here.

\section{EINLEITUNG}

Vielfältige Gegenstände aus Knochen und Geweih sowie Tierzähne verschiedener Varianten sind in den Fundkontexten der Vekerzug-Kultur (weiter VK) keine Seltenheit und einige von ihnen sind als die lokale Besonderheit ihrer Formenwelt anzusehen. Die Verzierung in Form geometrischer Muster und figürlicher Darstellungen auf manchen Knochen- und Geweihartefakten ist zudem eine der grundlegenden Quellen für die Rückschlüsse auf die Geisteshaltung der Bevölkerung der VK.

Eine Publikation, die ausführliche Ausblicke auf das Gesamtvorkommen der untersuchten Fundgruppe gibt, steht bisher noch aus. Die vorliegende Studie hat daher zum Ziel, die einzelnen Knochen-, Geweih- und Zahnartefakte aus den Fundstellen der VK in Ostungarn und der Slowakei ${ }^{2}$ möglichst vollständig vorzulegen, typenmäßig zu gliedern und chronologisch bzw. kulturell einzuordnen. Zudem wird die Funktionszuweisung einiger Fundtypen aus Knochen und Geweih einer kritischen Betrachtung unterzogen. Bedeutend ist zweifellos auch die Frage, inwieweit sich an der behandelten Fundgruppe überregionale Beziehungen der VK ablesen lassen. Dies ist vor allem für die Beurteilung der oft diskutierten, aber unbegründet überschätzten östlichen Einwirkungen in der VK wichtig.

Einem relativ hohen Anteil an fertigen Knochen- und Geweihgegenständen aus den Gräbern stehen wenige solche Funde sowie eine fast völlige Abwesenheit der Zahnartefakte auf den Siedlungen gegenüber, was wohl auch mit dem mangelhaften Publikationsstand der meisten Siedlungskomplexe

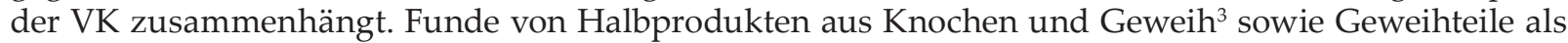

1 Diese Arbeit wurde als Wirkungsindikator der Projektnachhaltigkeit ITMS: 26220120059.

2 Aus nicht zahlreichen Fundkomplexen der VK in Nordwestrumänien sind derzeit keine Knochen-, Geweih- und Zahnartefakte vorhanden.

3 Z. B. Chotín VII, Mužla-Čenkov, Lipová-Ondrochov, Salgótarján-Ipari-park II, Tiszalök-Börtön (Kuzma 2011, 82; Romsauer) Hečková/Repka 2019, 43; Scholtz 2010, 80, 85; Točík 1987, 247; Vaday 2000, 35). 
Rohmaterial ${ }^{4}$ kommen dagegen nur auf den Siedlungen zutage. Einige Knochen- und Geweihartefakte sind Zufallsfunde. Aus einigen Siedlungen sind aber die ausführlichen archäozoologischen Bestimmungen tierischer Überreste vorhanden, ${ }^{5}$ wobei solche Daten für Tierknochen aus den Gräbern bisher in geringer Anzahl vorliegen (Kozubová 2013a, 285 ff.). ${ }^{6}$ Als etwas problematisch erweisen sich auch einige archäozoologische Bestimmungen der fertigen Artefakte nicht nur zu den Tierarten, sondern auch zur Unterscheidung zwischen Knochen und Geweih.

\section{AUSWERTUNG DER FUNDE}

Die im Fundgut der VK vorkommenden Knochen-, Geweih- und Zahnartefakte, deren typologisches Spektrum sowie chronologische Aussagekraft verhältnismäßig begrenzt sind, lassen sich in folgende Funktionsgruppen unterteilen: Waffen und Zubehör, Pferdegeschirr und Reiterausrüstung, Werkzeuge und Geräte, Schmuck, Toilettegeräte und sonstige Objekte, denen alle Gegenstände ohne eindeutige Funktion zugerechnet wurden. Eine Sondergruppe von Knochen-/Geweihfunden bilden die kleineren hohlen Zylinder mit (oder ohne) unterschiedlich angebrachten Löchern, bei denen auch anhand ihrer abweichenden Befunde vielseitige Verwendung anzunehmen ist. ${ }^{7}$

\section{Waffen und Zubehör}

Waffen sind vornehmlich aus Eisen gefertigt, ein weiteres Rohmaterial ist Bronze. Knochen und Geweih wurden in der VK nur zur Herstellung der Köcherteile und Griffauflagen der Streitmesser verwendet. Einzige Knochenwaffe im Fundmaterial der VK ist derzeit eine Pfeilspitze mit quadratischem Querschnitt und Innentülle aus dem HaD1-zeitlichen Körpergrab 3/k von Senec-Štrková kolónia (Abb. 1: 5). Bei Knochenpfeilspitzen des sog. östlichen Typs sind rahmenhaft zwei Verbreitungsschwerpunkte zu beobachten - in der Ciumbrud-Kultur Siebenbürgers, wo ihr Vorkommen chronologisch aufs 7. Jh. und die erste Hälfte des 6. Jhs. v. Chr. beschränkt ist, und insbesondere im Waldsteppen- und Steppengebiet Osteuropas und im Nordkaukasus, wo gleich mehrere Typen und Varianten vertreten sind, die während der ganzen Skythenzeit dort im Gebrauch waren (Hellmuth 2006, 128-135, 137-144; Kozubová 2009, 84 ff.). Anhand der bisherigen Untersuchungen zum Vekerzuger Waffenkanon ist die Abwesenheit der Knochenpfeilspitzen im Sachgut der VK nicht überraschend und bestätigt nur die Feststellungen, dass die Waffenausstattungen der VK sich von den Bewaffnungsschemata nicht nur der zeitgleichen Ciumbrud-Kultur, sondern auch der Westpodolien-Kultur und der Gruppierungen im Waldsteppenteil der Dnjeprregion deutlich unterscheiden (Kozubová 2019b, 86).

In der VK wurden aus Geweih/Knochen kreuzförmige und zoomorph dekorative Köcherteile hergestellt, die im Vergleich zu den relativ zahlreichen metallischen Köcherbeschlägen nur mit wenigen Exemplaren vertreten sind (siehe Kozubová 2009, 99-112). Die ältesten Verzierungselemente der Köcher aus der beginnenden Stufe HaD1 stellen zwei zoomorphisch gestalteten Köcherteile mit Kreisaugenverzierung aus dem Körpergrab 31 von Törökszentmiklós-Surján und dem Brandgrab 320 von Tiszalök-Börtön dar, ${ }^{8}$ für welche wir keine entsprechenden Vergleiche kennen (Abb. 1: 3; 2: 12). Sie zählen so zur lokalen Besonderheit der VK. ${ }^{9}$ Kreuzförmige dekorative Köcherteile, die vor allem aus Bronze gefertigt wurden, sind dagegen etwas jünger und waren nicht nur im Karpatenbecken (VK, Ciumbrud-Kultur bzw. Bîrseşti-Gruppe), sondern auch im osteuropäischen Steppen- und Waldsteppengebiet im Laufe des entwickelten HaD1, des kompletten HaD2 und des beginnenden HaD3 im

4 Eine Ausnahme ist das Brandgrab 16 von Muhi-Kocsmadomb, wo 5 Fragmente von Hirschgeweih gefunden wurden (Kemenczei 2009, 127).

5 Z. B. Balassagyarmat-Káposztások, Békéscsaba, Ecser 6-Maglód 1, Hernádvecse, Ludányhalászi-Sóderbánya, Nagytarcsa, Salgótarján-Ipari park II, Svodov (Czifra u. a. 2017, 283-289 mit anderer Literatur; Podborský 1955, 481; Tugya 2010).

6 Z. B. Csanytelek-Újhalastó, Orosháza-Gyopáros (Galántha 1981, 50; 1986, 73; Juhász 1972, 214; 1976, 241).

7 In den Anmerkungen werden die folgenden Abkürzungen verwendet: KG - Körpergrab; BG - Brandgrab; SO - Siedlungsobjekt.

8 Die Anwesenheit einer Rückenöse auf langem senkrechtem Arm verbindet das Exemplar von Tiszalök morphologisch mit den kreuzförmigen Köcherbeschlägen.

9 Die chronologische Einordnung basiert einerseits auf den Beifunden (BG von Tiszalök; Abb. 2) und andererseits auf der Datierung von ähnlichen Tierdarstellungen auf den Zierscheiben von Kelermes (Galanina 1997, Taf. 20: 55-59). 


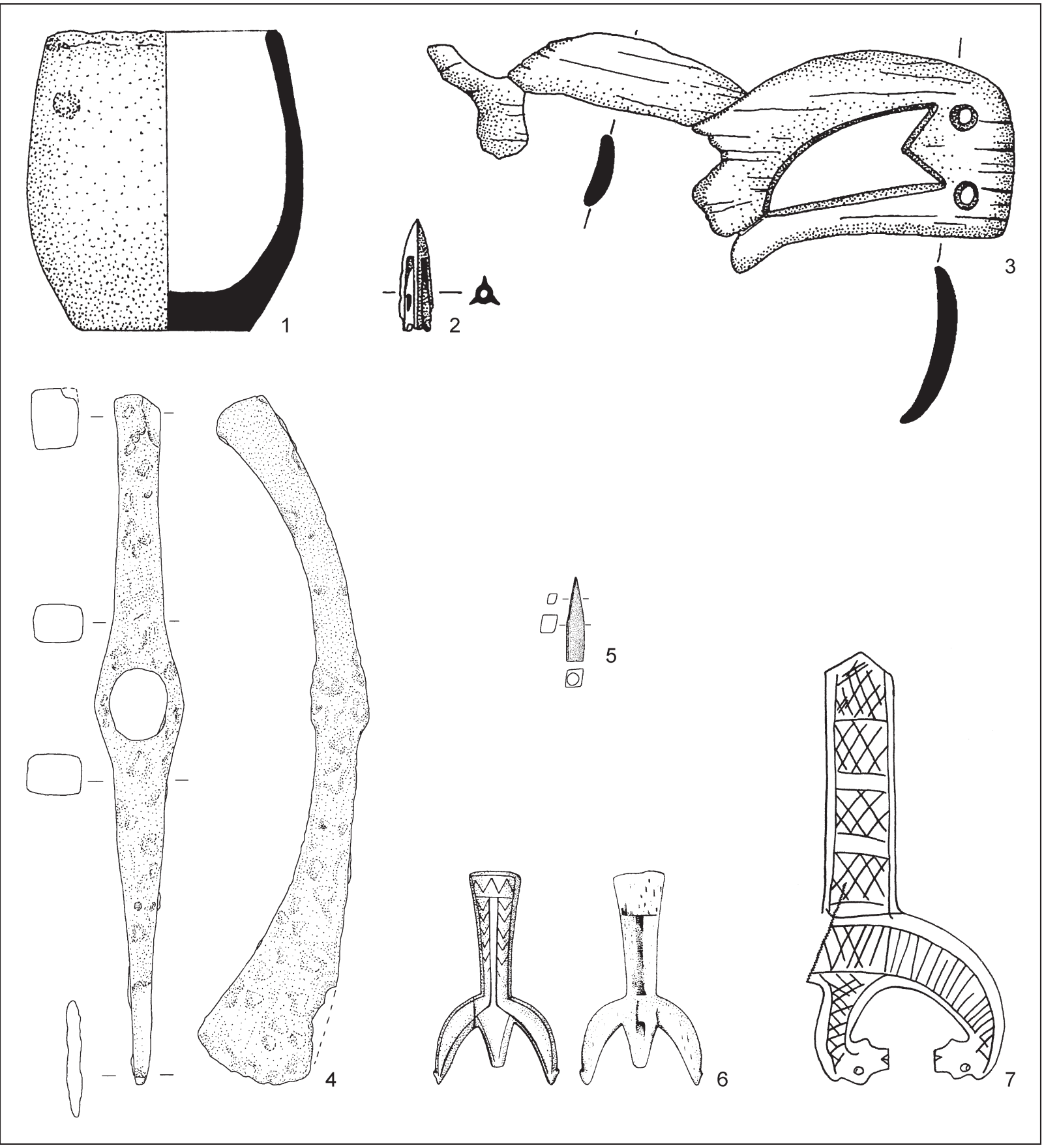

Abb. 1. Waffen und Zubehör aus Knochen und Geweih aus den Fundstellen der Vekerzug-Kultur. 1-3 - Törökszentmiklós-Surján, Körpergrab 31 (nach Kemenczei 1986, Abb. 6: 11, 12; 7: 1); 4, 5 - Senec-Štrková kolónia, Körpergrab 3/k (nach Kozubová 2013b, Taf. 122: 14); 6 - Szendrő-Höhle (nach Kemenczei 1986, Abb. 8: 2); 7 - Košice (nach Párducz 1965, Abb. 9: 2). Verschiedene Maßstäbe.

Gebrauch. Beide Knochenexemplare sind Zufallsfunde, wobei das geometrisch verzierte Fundstück aus Szendrő dem Typ II nach A. Kozubová angehört, der sich chronologisch auf die Späthallstattzeit, vor allem auf HaD2, beschränkt (Abb. 1: 6). Das Exemplar aus der Umgebung von Košice mit pferdekopfförmig gestalteten kurzen Armen ist dagegen der Variante I3 nach A. Kozubová zuzuordnen, die nur aus den ostkarpatenländischen Fundstellen - in erster Linie aus der VK - vorliegt (Abb. 1: 7; Kozubová 2019a, 66 f.). Auch das knöcherne Plättchenfragment in Form des realistisch dargestellten Pferdekopfes mit Mähne aus dem HaD1-zeitlichen Körpergrab 2 von Szentes-Vekerzug stammt aus einem kreuzförmigen Köcherteil der Variante I3 (Csallány/Párducz 1944-1945, 106, Taf. XLII: 5a, 5b). Im Falle 


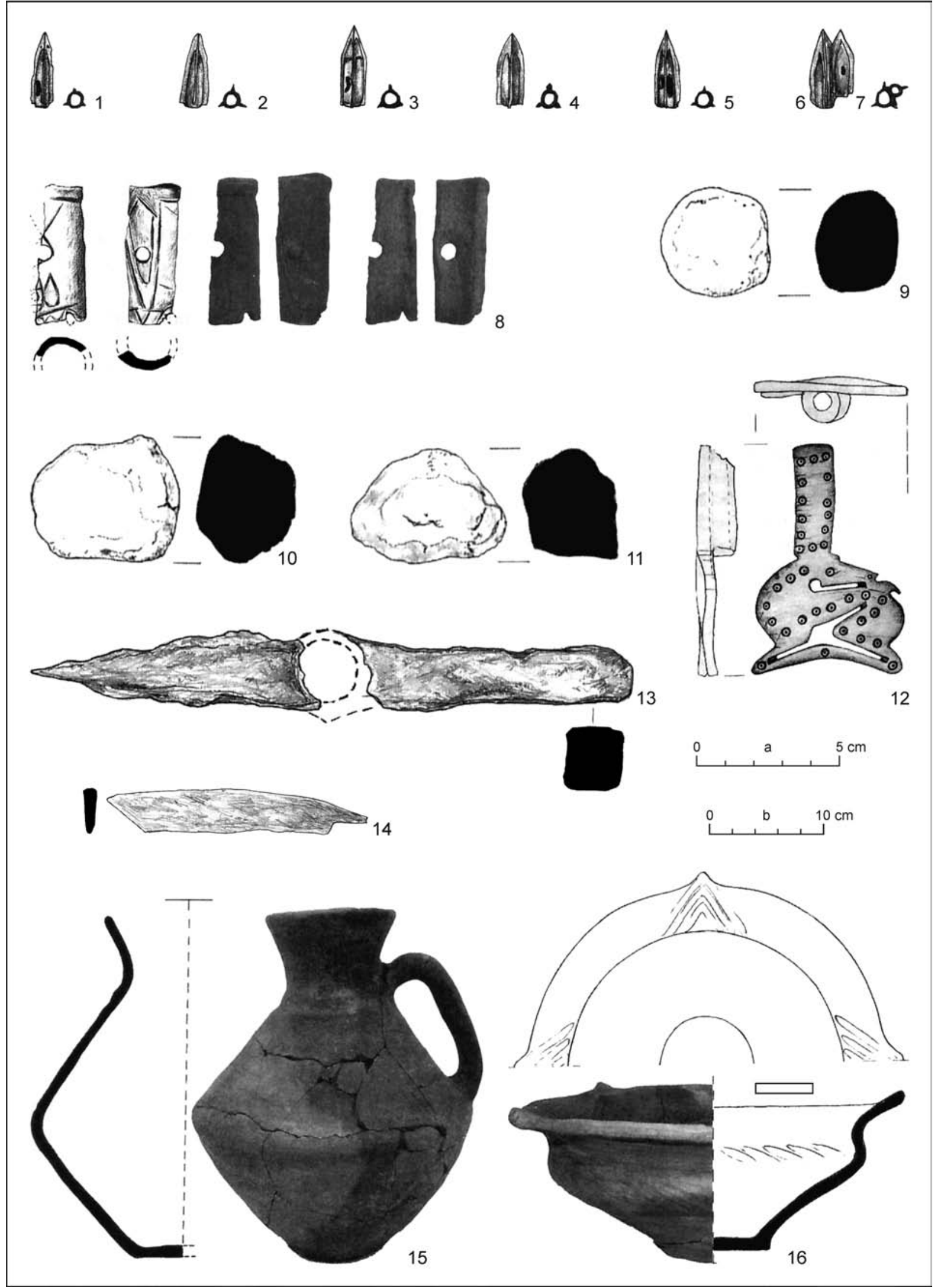

Abb. 2. Tiszalök-Börtön. Brandgrab 320 (nach Scholtz 2006, Abb. 5). Maßstab: a - 1-14; b - 15, 16. 


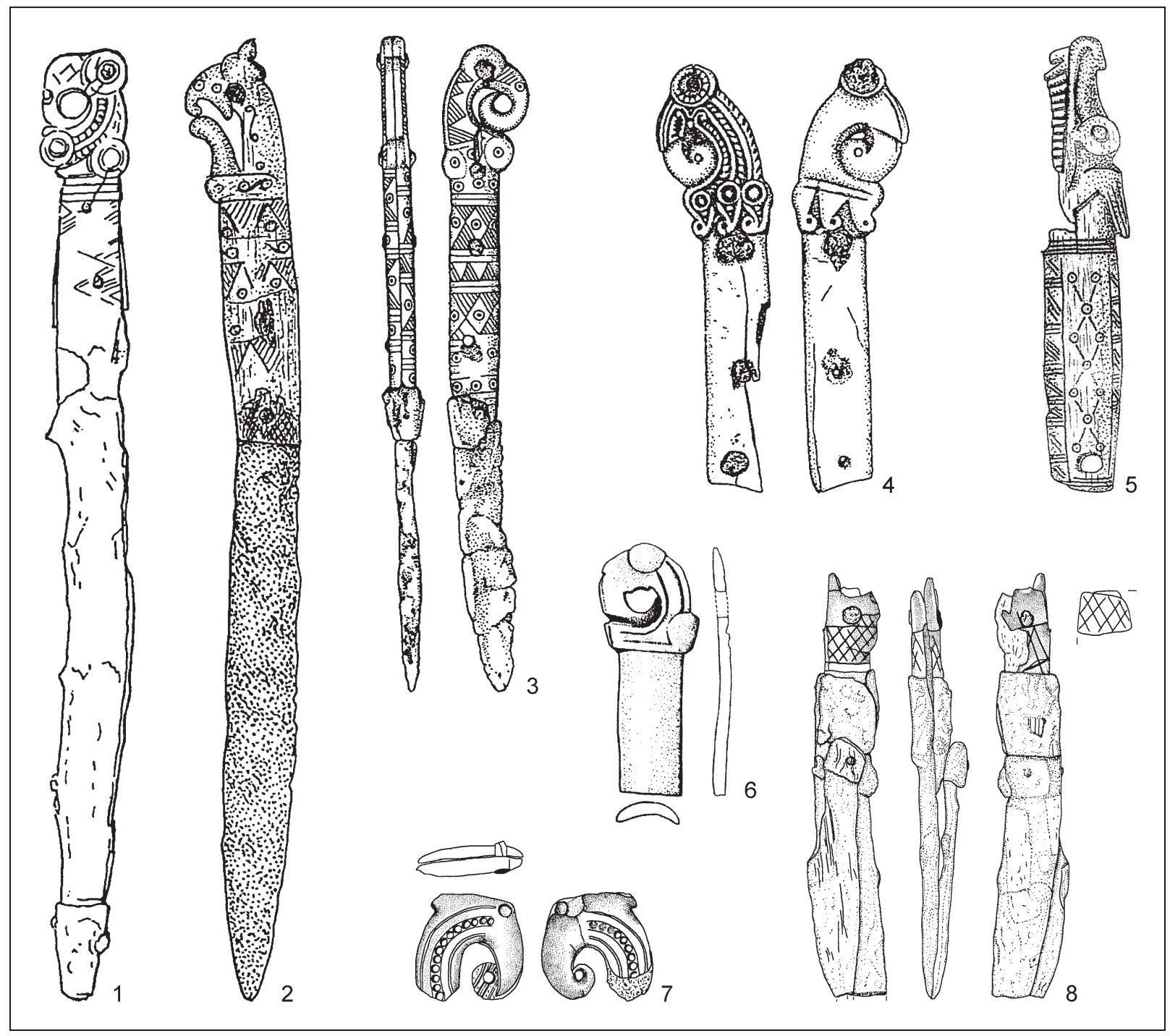

Abb. 3. Streit- und Arbeitsmesser mit verzierter Griffauflage aus Geweih und Knochen aus den Fundstellen der Vekerzug-Kultur. 1 - Szentes-Vekerzug, Körpergrab 120 (nach Kemenczei 2009, Taf. 77: 1); 2 - Csárdaszállás-Hanzélitanya, Körpergrab 17 (nach Kemenczei 2009, Taf. 16: 10); 3 - Vel'ký Grob, Siedlungsobjekt 2/82 (nach Kemenczei 2009, Taf. 185: 11); 4 - Nyíregyháza-Mandabokor, Siedlungsobjekt 446 (nach Kemenczei 2009, Taf. 54: 6, 7); 5 - Lajosmizse, Siedlungsfund (nach Kemenczei 2009, Taf. 30: 6); 6 - Mužla-Čenkov, Siedlungsobjekt 823 (nach Kuzma 2011, Abb. 10: 2, 6); 7 - Chotín IA, Körpergrab 13/52 (nach Kozubová 2013b, Taf. 38: 14, 14a); 8 - Chotín IA, Brandgrab 67/53 (nach Kozubová 2013b, Taf. 19: 12, 12a, 12b). Verschiedene Maßstäbe.

des Typs I ist eine Beliebheit besonders im entwickelten HaD1 und dann auch im HaD2 festzustellen (Kozubová 2009, 106, 108 f.). Mit Ausnahme von einem kreuzförmigen Geweihexemplar der Variante I3 aus dem Siedlungsobjekt 2 von Roşiori-Dulceşti sind dekorative Köcherteile aus Geweih bzw. Knochen außerhalb der VK nicht belegt und daher nur für den Formenschatz der VK typisch (Hânceanu 2019, Abb. 3). Obwohl die zoomorphe Verzierung auf den kreuzförmigen Köcherteilen mit Ausnahme von Pferdekopfmotiv ihre Vorbilder im sog. skythisch-sibirischen Tierstil aufweist, deuten einige Indizien an, dass die karpatenländischen kreuzförmigen Köcherteile formenkundlich nicht unbedingt von östlichen Exemplaren abgeleitet sein mussten und vom Osten nur einige Verzierungsmotive übernommen waren (Kozubová 2019a, 67 f.)

Eine Sondergruppe von Stichwaffen stellen die mehr als $20 \mathrm{~cm}$ langen Griffplattenmesser mit aus Geweih oder Knochen hergestellter und geometrisch reich verzierter Griffauflage dar, die in einer mehr oder weniger realistischen beiderseitigen Raubvogelkopfdarstellung (Adlerkopf) endet. Bisher sind drei solche Streitmesser im Fundmaterial der VK zuverlässig nachgewiesen - aus dem Brandgrab 110 von 
Abony-Blaskó-dűlő, dem Körpergrab 17 von Csárdaszállás-Hanzélitanya und dem Körpergrab 120 von Szentes-Vekerzug, dort sogar mit einem eisernen Ortband (Abb. 3: 1, 2; Polgár 2007, 318, Abb. 26). ${ }^{10}$ Beifunde aus diesen Bestattungen sind zwar chronologisch nicht signifikant, für einen Datierungsansatz ins 6. Jh. v. Chr. (eher in seine zweite Hälfte) spricht aber das Perlschnurmotiv auf dem Exemplar von Szentes-Vekerzug. Das Motiv begegnet zahlreich auf den bronzenen Zierraten in Form des Adlerkopfes, vor allem in der Mitteldnjeprregion, wo sie vorwiegend ins letzte Viertel des 6. Jhs. und ins erste Viertel des 5. Jhs. v. Chr. datiert sind (Korol'kova 2006, 102, Taf. 21: 8, 12-15, 17, 18). Der bronzene kreuzförmige Köcherbeschlag aus Brandgrab 90 von Törökszentmiklós-Surján beweist das erste Auftreten von Perlschnurmotiv im Karpatenbecken jedoch schon im Laufe der entwickelten Stufe HaD1 (Kozubová 2013a, 105). Obwohl die Adlerkopfdarstellungen im Laufe der ganzen Skythenzeit in Osteuropa und Nordkaukasus weit verbreitet waren, sind Streit- sowie Arbeitsmesser mit organischer Griffauflage mit zoomorpher Endgestaltung und geometrischer Verzierung nur dem Sachgut der VK eigen und besitzen dort ihre Haupverbreitung. Im osteuropäischen Steppen- und Waldsteppenraum sowie im Nordkaukasus treten so verzierte Messer dagegen nur höchst selten auf. ${ }^{11}$ Auf ihre heimische Produktion im östlichen Karpatenbecken weisen u. a. geometrische Verzierungselemente, wie z. B. schraffierte Dreiecke, Rauten oder Kreisaugen, die zahlreiche Entsprechungen im Repertoire der osthallstättischen Verzierungsmotive finden und auf den Messern aus Osteuropa nicht vorhanden sind (Kemenczei 2005, 185).

\section{Pferdegeschirr}

Im Fundgut der VK sind Elemente der Pferdeschirrung aus Knochen/Geweih derzeit nur durch drei Knebel mit zoomorphisch ausgearbeiteten Enden und wenige Riemenzierrate vertreten. Einige zylindrische Gegenstände aus Knochen/Geweih sind als Bestandteile von Reitpeitschen anzusehen.

Die Hauptkomponente der Pferdeschirrung in der VK bilden eiserne Trensen, die anhand der einzelnen konstruktiven Merkmale einem Typ angehören. Dieser zeichnet sich durch die Vernietung des Mundstückes mit den Seitenknebeln aus und ist in der Fachliteratur unter der Bezeichnung als Typ Szentes-Vekerzug bekannt. Das Vorkommen von anderen, im Fundmaterial der VK höchst selten vorhandenen Typen, wie z. B. von platten- und stabförmigen Geweihknebeln mit drei Löchern im Mittelteil und einem als Tierhuf gestalteten Außende, ist daher ohne Bedeutung für die Beurteilung der Entwicklung und des gesamten Gepräges des Vekerzuger Pferdegeschirres. Ein ganz erhaltener stangenförmiger und eingerartiger Geweihknebel ohne nähere Entsprechungen stammt aus dem Siedlungsobjekt 487 von Pusztataskony-Ledence 1, zwei andere unvollständige Exemplare wurden im Körpergrab von Mátraszele aus der entwickelten Stufe HaD1 und im Siedlungsobjekt 128 von Budapest-Rákospalota-Újmajor (plattenförmig) gefunden (Abb. 4: 1, 5; M. Horváth 2002, 106, Abb. 10: 6). Zoomorphe Knebel aus Knochen und Geweih sind weit in frühskythenzeitlichen Fundkomplexen, insbesondere im ukrainischen Waldsteppengebiet und weniger auch im Kaukasus verbreitet, ${ }^{12}$ wobei ihre beiden Enden stets mit einem Tierkopf und einem Tierhuf verziert sind (Mogilov 2008, 24-29, Abb. 40-56; Polidovič 2004, 145, 147-151, Abb. 2, 3). Anhand der formenkundlichen Unterschiede zu osteuropäischen Vorbildern sind beide Knebel von Pusztataskony und Rákospalota-Újmajor als Erzeugnisse lokaler Werkstätten anzusehen. ${ }^{13}$ Die zoomorphen Geweih- bzw. Knochenknebel sind im Karpatenbecken zwar fremd, der Behauptung von M. F. Tóth, dass ihres Vorkommen in der VK mit Migrationsverschiebungen aus dem Waldsteppenund Steppenraum Osteuropas nach Ostungarn in Verbindung steht, kann man aber nicht zustimmen

10 Im Inventar des Brandgrabes 238 von Tápiószele-Szumrák fand sich ein Streit- oder Hiebmesser mit knöcherner, unverzierter Griffauflage, das aber in der Publikation von M. Párducz $(1966,56)$ nicht abgebildet ist.

11 Solche Messer sind aus Olefirščina, Berestnjagi und Aleroevsko-I bekannt (Kovpanenko 1981, Abb. 2: 5; Kulatova/Lugovajal Suprunenko 1993, Abb. 6: 1; Vinogradov 1972, Abb. 45: 1).

12 Dort wird ein sporadisches Weiterleben von Knebeln dieser Art bis zum Ende des 6. Jhs. v. Chr. beobachtet. Im Steppengebiet fehlen sie dagegen fast vollständig (Polidovič 2004, 149, 151).

13 Die Löcher im Mittelteil der osteuropäischen Exemplare sind gewöhnlich durch eine Verdickung von den Seitenteilen abgesetzt. Neben den Geweihknebeln aus den Fundstellen der VK liegen in der nordostalpinen Region nur zwei weitere Fundstücke vor. Der Knebel aus der Býčí skála-Höhle ähnelt morphologisch dem Exemplar aus der Siedlung von BudapestRákospalota-Újmajor und ist daher für ein lokales, wahrscheinlich mit der VK verbundenen Erzeugnis anzusehen. Der Geweihknebel aus Celldömölk-Sághegy findet seine Entsprechungen dagegen eher unter den osteuropäischen Exemplaren (Mozsolics 1953, 94, Abb. 35; Taf. XV: 8; Parzinger/Nekvasil/Barth 1995, Taf. 31: 325). 


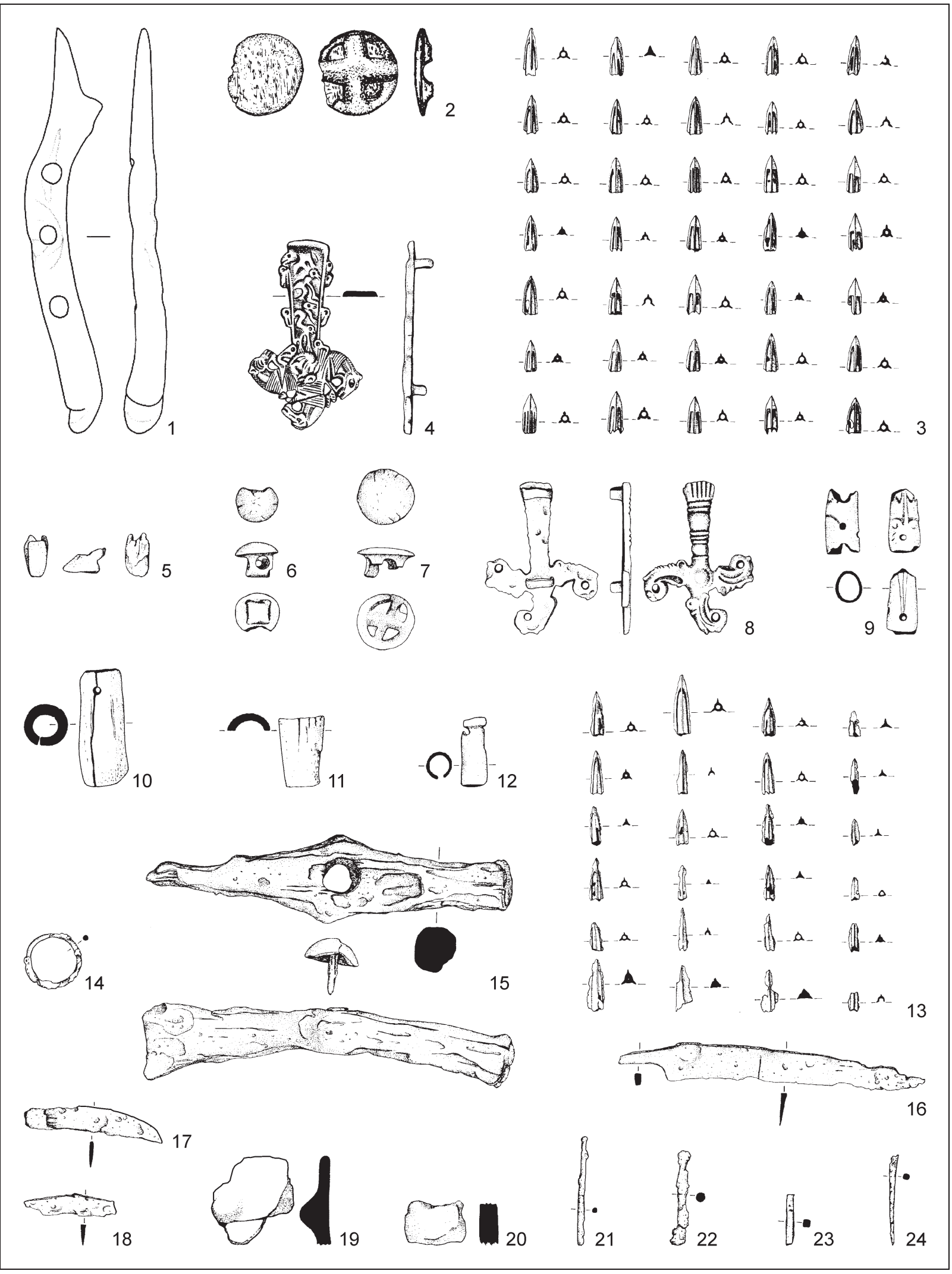

Abb. 4. Pferdegeschirr aus Geweih und Knochen aus den Fundstellen der Vekerzug-Kultur. 1 - Pusztataskony-Ledence 1, Siedlungsobjekt 487 (nach F. Tot 2015, Abb. 2); 2 - Sándorfalva-Eperjes, Grab 136 (nach Galántha 1985, Abb. 7: 7a, 7b); 3-7 - Mátraszele, Körpergrab (nach Kemenczei 1986, Abb. 3); 8-24-Cegléd-Hordógyár, Körpergrab (nach Kemenczei 1986, Abb. 4; 5). Verschiedene Maßstäbe. 
(F. Tot 2015, 304). Das Vorkommen solcher Knebel besaß in der VK nur einen episodischen Charakter ohne ihre Aufnahme in der lokalen Pferdeschirrung.

Das Riemenzubehör bildet in der VK typologisch eine sehr heterogene Fundgruppe, die aber fast keine Relevanz für lokales Pferdegeschirr besitzt und in ersten Linie aus Bronze hergestellt wurde. Im Gegensatz zur Hallstattkultur und zum Steppen- und Waldsteppengebiet Osteuropas sind die Riemenzierrate aus Bronze und Knochen in der VK nicht integraler Bestandteil der Pferdeschirrung und damit auch ihres Sachgutes geworden (Kozubová 2019a, 93 f.). Unter den Knochenexemplaren sind drei Typen nachweisbar: vier Ringfuß- und Quadratfußknöpfe mit unverzierter kalottenförmiger Oberseite (Abb. 4: 6, 7) ${ }_{1}^{14}$ zwei zylindrische Riemenverteiler ${ }^{15}$ und ein unvollständig erhaltener Knopf mit flacher Oberseite und im rechten Winkel überkreuzenden Ösen (Abb. 4: 2). ${ }^{16}$ Vier kleine runde Zierscheiben mit einer Rückenöse sind für die multifunktionalen Objekte - Riemenzierrate und Trachtelemente - zu halten, die sich in der VK chronologisch auf die Stufe HaD1 beschränken. ${ }^{17}$ Zwei Provenienzgruppen von Riemenzierraten sind in der VK festgestellt, wobei beide vor allem nach $\mathrm{HaD1}$ zu datieren sind. Die

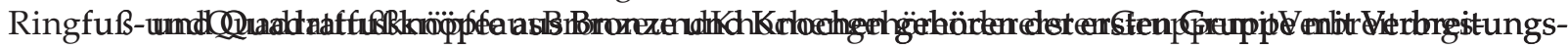
schwerpunkt in der Osthallstattkultur an, der zweiten Gruppe mit Hauptverbreitung vor allem in den frühskythenzeitlichen Fundkomplexen im Nordkaukasus und Waldsteppengebiet Osteuropas sind zylindrische Riemenverteiler und wohl auch der Knopf aus Sándorfalva-Eperjes zuzuordnen (Machortych 2017, 167-172, Abb. 1; 2; Metzner-Nebelsick 2002, 303, 310 f., 316 ff., Abb. 139A; 140A; 143; Mogilov 2008, 70, 71, Abb. 126: 1-17; 130: 11-44; 132; 133: 1-21). Für das Pferdegeschirr der VK ist auch ein höchst sporadisches Vorkommen von durchbohrten Bären- und Eberzähnen kennzeichnend. Diese Art der Riemenzierrate ist derzeit nur im Körpergrab 220/54 von Chotín IA und in der Pferdebestattung 146 von Szentes-Vekerzug zuverlässig belegt, was im deutlichen Unterschied zu ihrer Beliebtheit in Osteuropa steht (Kozubová 2011, 91 f.; 2013b, 93 f., Taf. 76: 3-6; Mogilov 2008, 84, 85, Abb. 153; 154; Párducz 1955, 10, Taf. XII: 7).

\section{Werkzeuge und Geräte}

Neben den Befunden auf den Siedlungen sind für die Einschätzung der Wirtschaftsweise der VK auch Geräte und Werkzeuge von besonderer Bedeutung. Es handelt sich um Funde verschiedener Zweckbestimmung meistens ohne chronologische Relevanz, die nicht nur aus den Siedlungen, sondern häufig auch aus den Gräbern vorliegen und hauptsächlich aus Eisen, Ton sowie Stein und weniger aus Bronze, Knochen und Geweih gefertigt wurden (Kozubová 2013a, 119-128, 136 ff.). Es ist aber überraschend, dass Geräte und Werkzeuge aus Knochen/Geweih im Spektrum der Vekerzuger Funde verhältnismäßig selten vorkommen. Zudem sind im behandelten Fundmaterial solche Typen vertreten, die bevorzugt aus Metall hergestellt wurden, wobei eine mögliche anwendungsspezifische Differenzierung zwischen den knöchernen und metallischen Exemplaren noch unbeantwortet bleibt. Zur Be- und Verarbeitung von Textil-, Leder- und Korbwaren wurden Nähnadeln aus Knochen benutzt. ${ }^{18}$ Wohl zu den multifunktionalen Werkzeugen zählen Knochenahlen bzw. -pfrieme und kurze zugespitzte Objekte, die meistens zur Verarbeitung von organischen Materialien verwendet werden konnten. ${ }^{19}$ Im Siedlungsobjekt 1/88 von Budkovce wurden in der VK der bisher einzige doppelkonische Spinnwirtel aus Knochen samt 14 Tonspinnwirteln und zwei Tonstempeln gefunden (Miroššayová 2018, 50, Taf. IV: 11, 13; V: 1, 3-15). Aus Geweih bzw. Knochen wurden zumindest teilweise die Griffauflagen eiserner Griffplattenmesser

14 KG von Mátraszele; SO 164 von Mezőkövesd-Mocsolyás; BG 1 von Muhi-Kocsmadomb (Kalicz/Koós 1998, Abb. 3: 2a, 2b; Kemenczei 2009, 170, Taf. 155: 1, 2; Leszih 1939, Taf. II: 15).

15 SO 26 von Budapest-Rákospalota-Újmajor; BG 12/06 von Ždaňa (M. Horváth 2002, 105, Abb. 10: 3; Miroššayová 2015, 72, Taf. XI: 2).

16 Grab 136 von Sándorfalva-Eperjes (Galántha 1985, 123, Abb. 7: 7a, 7b).

17 BG 39 von Tiszavasvári-Csárdapart; BG 52 von Tiszavasvári-Dózsa-telep (Kemenczei 2009, 151, 155 f., Taf. 111: 8, 122: 9-11).

18 Z. B. SO 26, 199, 252, 254, 274, 374 von Budapest-Rákospalota-Újmajor; SO 15 von Gyulavári; SO 7/77, 17/77 von Chotín VII (Gyucha 2002, 62, Abb. 10: 5; M. Horváth 2002, 105, Abb. 10: 5; Romsauer/Hečková/Repka 2019, 198 f., Taf. III: 4; VI: 6; Tézer 2011, 101 ff., Abb. 16: 32; 22: 1; 23: 16; 27: 1).

19 Z. B. SO 254, 260 von Budapest-Rákospalota-Újmajor; SO 1/88 von Budkovce; SO 45/77, 46/77, 66/77 von Chotín VII; Siedlung von Tiszaszőlős-Csontospart III; KG 77 von Szentes-Vekerzug; BG 83 von Tápiószele-Szumrák (Cseh 2006, 18, Abb. 13: 9; Miroššayová 2018, 50, Taf. IV: 14; Párducz 1954, 39, Taf. XXIV: 17; 1966, 43, Taf. XV: 9; XVII: 4; Romsauer/Hečková/Repka 2019, 203, 203, Taf. XIV: 3; XV: 9; XIX: 1, 6; Tézer 2011, 102, Abb. 23: 17, 18; 25: 16). Unter den Beigaben des Brandgrabes 160 von Tápiószele wird eine Eisenahle mit Knochengriff angegeben, die in der Publikation von M. Párducz $(1966,50)$ aber nicht abgebildet ist. 
hergestellt, ${ }^{20}$ die geometrisch und/oder zoomorphisch verziert sind. Messer mit verzierter organischer Griffauflage gehören in der VK eher zu Ausnahmefunden (Abb. 3: 8). Obwohl sich ihre Verzierung nicht deutlich von solcher auf den Griffauflagen der Streitmesser unterscheidet, ist bei Arbeitsmessern eine Vorliebe für einfache geometrische Verzierungselemente, bestehend aus Kreisaugen, Netzmotiven, schraffierten Rauten und verschiedenen Linien, zu beobachten. ${ }^{21}$ Eine Ausnahme ist das Exemplar aus dem Siedlungsobjekt 2/82 von Vel'ký Grob, dessen zur Klinge disproportional lange und geometrisch verzierte Griffauflage (9,3 kontra 13,7 cm) in einer realistischen beiderseitigen Raubvogelkopfdarstellung endet (Abb. 3: 3; Farkaš 1986, 169 f., Abb. 4: 1, 2). Der Adlerkopf ist regelmäßig mit eingeschnittenen schraffierten Dreiecken bedeckt und entspricht in manchen Details den gleich großen Fundstücken aus dem Körpergrab 13/52 von Chotín IA und dem Körpergrab 120 von Szentes-Vekerzug, die anstatt der Dreiecke mit einer Perlschnur verziert sind (Abb. 3: 1, 7). Der unvollständige Erhaltungszustand des Exemplars von Chotín sowie der drei weiteren Messer aus den Siedlungen von Lajosmizse (mit einer hundeartigen Darstellung, wohl Wolfskopf), Nyíregyháza-Mandabokor (mit beiderseitigem Adlerkopf) und Mužla-Čenkov ${ }^{22}$ erschwert eine zuverlässige Zuordnung entweder zu den Arbeits- oder den Streitmessern (Abb. 3: 4-6). Nur das Siedlungsobjekt 823 von Mužla-Čenkov mit Grafittonkeramik und Schüsseln mit grafitiertem Gittermuster auf der inneren Oberfläche bietet sichere Anhaltspunkte für eine zeitliche Einordnung in die Späthallstattzeit (Kuzma 2011, 86). ${ }^{23}$ Im Fundgut der VK sind derzeit überraschenderweise keine Geweihgriffe von eisernen Griffangelmessern zuverlässig nachgewiesen, die zusammen mit Griffplattenmessern mit geometrisch verzierter organischer Griffauflage als typische Fundformen des osthallstättischen Milieus anzusehen sind (Müller 2012, 244 f., Taf. 36: 2; Parzinger/Nekvasil/Barth 1995, 81, Taf. 45: 405; Stöllner 2002, 102 ff.; Tecco Hvala 2012, 135 ff.). Obwohl die eisernen Arbeitsmesser in der VK in Gräbern beider Geschlechter vorkommen, sind diese öfter in Männer- als in Frauenbestattungen vorhanden, was anhand der vorliegenden anthropologischen Daten sowie eindeutigen geschlechtsspezifischen Beigabentypen auch die Exemplare mit erhaltener organischer Griffauflage bestätigen (Kozubová 2013a, 173 f., 177, 195, 197 f.). Bemerkenswert ist auch, dass die Hälfte der Messer mit zoomorphisch verzierter Griffauflage aus Siedlungen stammt.

\section{Toilettegeräte}

$\mathrm{Zu}$ einer eigenartigen Fundkategorie zählen wenige Toilettegeräte, die im Fundmaterial der VK durch zweiteilige Rasiermesser und metallische Spiegel mit seitlichem Handgriff vertreten sind. Die Rasiermesser bestehen aus einer kurzen eisernen Klinge und zwei an beiden Enden mittels eines Nietes zusammengehaltenen Knochen- oder Geweihschalen, die als Futteral für die Klinge und zugleich als Handgriff dienen. Durch einen der beiden Nieten am Griffschalenende wird auch die Klinge mit Futteral/Handgriff beweglich zusammengehalten (Abb. 5: 4). Das Exemplar aus dem Grab von BátmonostorSzurdok ist ganz aus Eisen gefertigt (Abb. 6: 17). Manchmal kommen auch eine Befestigungshülse und eine bronzene Hängeöse vor. Oft begegnet man im Zusammenhang mit Rasiermessern einer funktional Bezeichnung als knöcherne Messergriffe (z. B. Dušek 1966, 31; Chochorowski 1985, 80 f.; Stegmann-Rajtár 2009, 84) oder als Taschen- bzw. Klappmesser (z. B. Ramsl 2002, 86; Stöllner 2002, 103; Tecco Hvala/Dularl Kocuvan 2004, 184). Der ersten Interpretation widerspricht vor allem die Lage der Niete nur an den Griffschalenenden, im Unterschied zu Messern mit organischer Griffauflage, wo Niete am Griff auch im Mittelteil angebracht waren. Die Gesamtkonstruktion dieser Funde macht zudem einen nicht stabilen Eindruck mit Rücksicht auf ihre häufige Verwendung beim Schneiden von härteren Materialen oder beim Ausüben eines anderen Drucks auf die Klinge. Deshalb erweist sich ihre Verwendung als Rasiermesser für höchstwahrscheinlich (Kozubová 2012, 66 f.; Tecco Hvala 2012, 136 f.).

${ }^{20}$ Die erhaltenen Abdrücke der Maserung auf den Griffen einiger Arbeitsmesser weisen auf die Verwendung von Holz zur Fertigung der Messergriffe sowie Griffauflagen hin, das sicher gegenüber Knochen und Geweih bevorzugt wurde (z. B. Kisfaludi 2004, 172, Taf. XIV: 4; Kozubová 2013b, 34, 39, 91, 131, 143, Taf. 26: 6; 31: 7; 73: 4, 4a; 104: 1, 1b; 116: 4).

21 SO 254 von Budapest-Rákospalota-Újmajor; BG 67/53 von Chotín IA; Siedlung von Salgótarján-Ipari-park II; BG 48 von Tápiószele-Szumrák; BG 52 von Tiszavasvári-Dózsa-telep; BG 4 von Tiszavasvári-Kapusz-lapos (Kemenczei 2009, Taf. 111: 11; Kozubová 2013b, Taf. 19: 12, 12a-c; Párducz 1966, 40, Taf. XIII: 2; XIV: 2; XXXI: 12; Scholtz 2008, 230, Abb. 3; Tézer 2011, 106, Abb. 23: 16; Vaday 2000, 35, Abb. 2: 12).

22 Dort kamen auch mehrere Halbfabrikate solcher Griffauflagen aus Geweih zutage (Kuzma 2011, Abb. 10: 1, 5, 6).

${ }^{23}$ Das Exemplar von Nyíregyháza ist vorläufig ans Ende des 6. Jhs. und an den Anfang des 5. Jhs v. Chr. datiert (Istvánovits 1997, 80). 

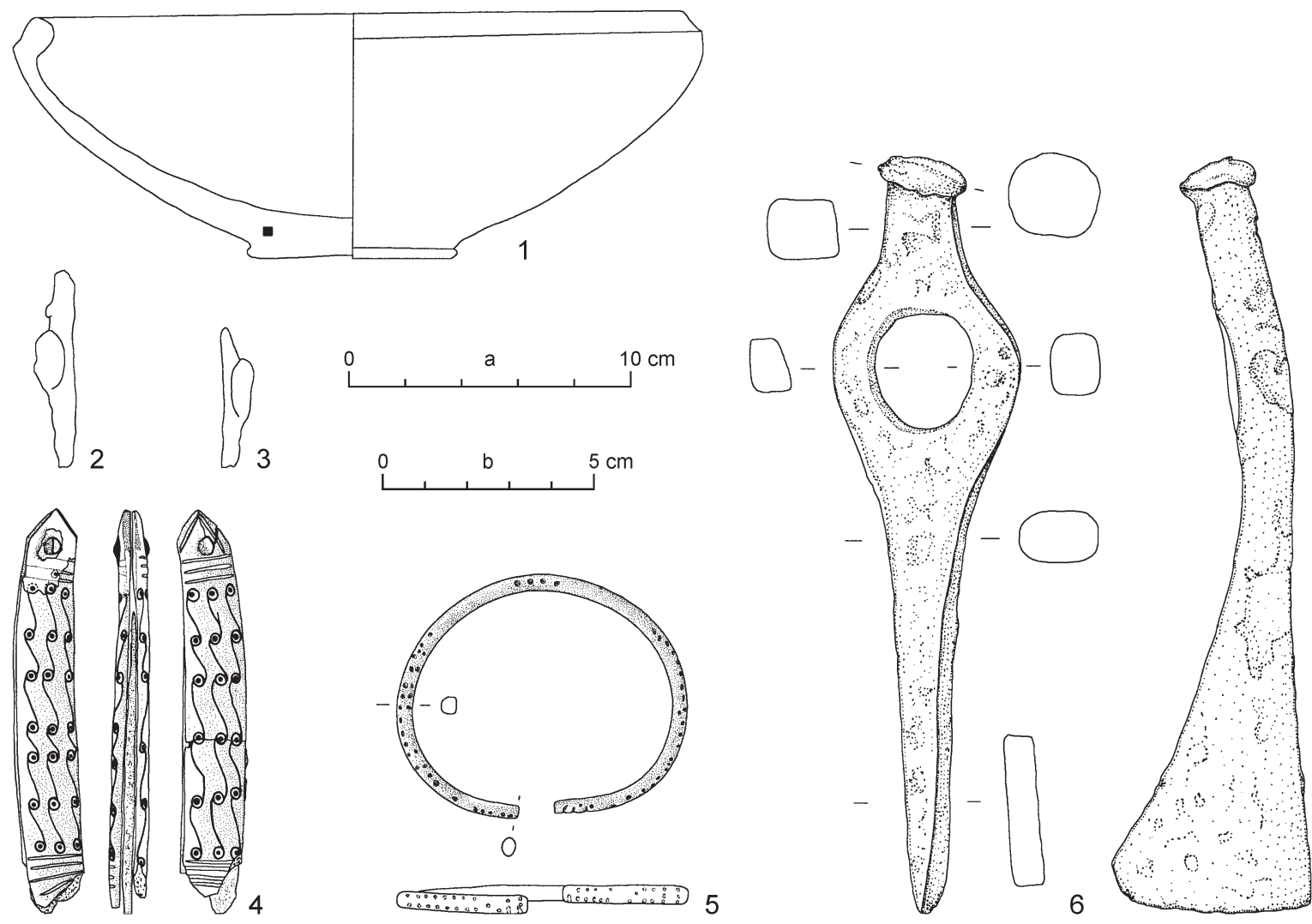

Abb. 5. Chotín IB. Körpergrab 46/61 (nach Kozubová 2013b, Taf. 101). Maßstab: a - 1; b - 2-6.

Wenige Rasiermesser dieser Konstruktion erscheinen auf dem relativ weiten Gebiet des eisenzeitlichen Mitteleuropas, wo drei Verbreitungsschwerpunkte zu beobachten sind - in der $\mathrm{VK}^{24}$ in der unterkrainischen Gruppe der Osthallstattkultur ${ }^{25}$ und auf dem Gräberfeld von Hallstatt. ${ }^{26}$ Zur weiteren Gruppe der Rasiermesser gehören die Funde aus den keltischen Flachgräberfeldern in Niederösterreich und Transdanubien, die auf das Überleben einiger hallstättischen Traditionen in der Latènezeit weisen und deren Konstruktionsdetails fast identisch mit den Klapprasiermessern aus den Fundstellen der VK und Hallstattkultur sind. Doch weichen die latènezeitlichen Exemplare von den hallstattzeitlichen durch ihre Verzierung ab (Nebehay 1993, Taf. 10: 9; Ramsl 2002, 86, Taf. 36: 165; Uzsoki 1987, Taf. 10; 11). Formenkundlich sind die Klapprasiermesser einheitlich und unterscheiden sich nur durch die Anwesenheit oder das Fehlen von geometrischer Ritzverzierung auf dem Knochengriff voneinander. Rasiermesser lassen sich in zwei Typen teilen - in die unverzierten Exemplare mit oder ohne Befestigungshülse als Typ I und in die verzierten Exemplare mit oder ohne Befestigungshülse als Typ II. Die einfache Verzierung besteht nur aus einzelnen Kreisaugen, die kombinierte dagegen aus Kreisaugen entweder mit verschiedenen Linien oder mit Horizontalbändern aus schraffierten Dreieckern oder mit Gittermuster. In der Auswahl einzelner Verzierungsmotive sowie in der chronologischen Einordnung der Rasiermesserfunde zeigen die drei Verbreitungsregionen gewisse Unterschiede. Während die Rasiermesser auf dem Gräberfeld

24 BG 68/54 und KG 220/54, 41/52 von Chotín IA; KG 46/61, 91/62 von Chotín IB; BG 12 von Maňa; KG 36 von Nyáregyháza; KG 41 von Orosháza-Gyopáros; KG 454 von Tápiószele-Szumrák (Benadik 1983, Taf. I: 5; Juhász 1976, 241, Abb. 4: 7; Kisfaludi 2004, Taf. XIII: 4-6; Kozubová 2013b, Taf. 20: 6-13; 44: 6; 75: 7, 14-16; 101: 4, 4a, 4b; 116: 3, 3a, 3b; Párducz 1966, Taf. LIV: $1-3)$.

25 Magdalenska gora-Preloge - Hügel 2/KG 38, 47, 69; Magdalenska gora - Hügel 4/KG 32; Novo mesto-Kandija - Hügel 1/KG 20; Stična - Hügel 48/KG 33 und 173 (Gabrovec u. a. 2006, Taf. 26: 20; 100: 4; Hencken 1978, Abb. 73 f.; Knez 1986, 69, Taf. 4: 2; Tecco Hvala/Dular/Kocuvan 2004, Taf. 36: 17, 18; 45: 13; 58: 3; 157: 5).

26 KG 233, 249, 706, 11/1889, 13/1939, BG 488b (Kromer 1959, Taf. 31: 8; 32: 21; 87: 4, 5; 145: 13a, 13b; 204: 9; 210: 16). 


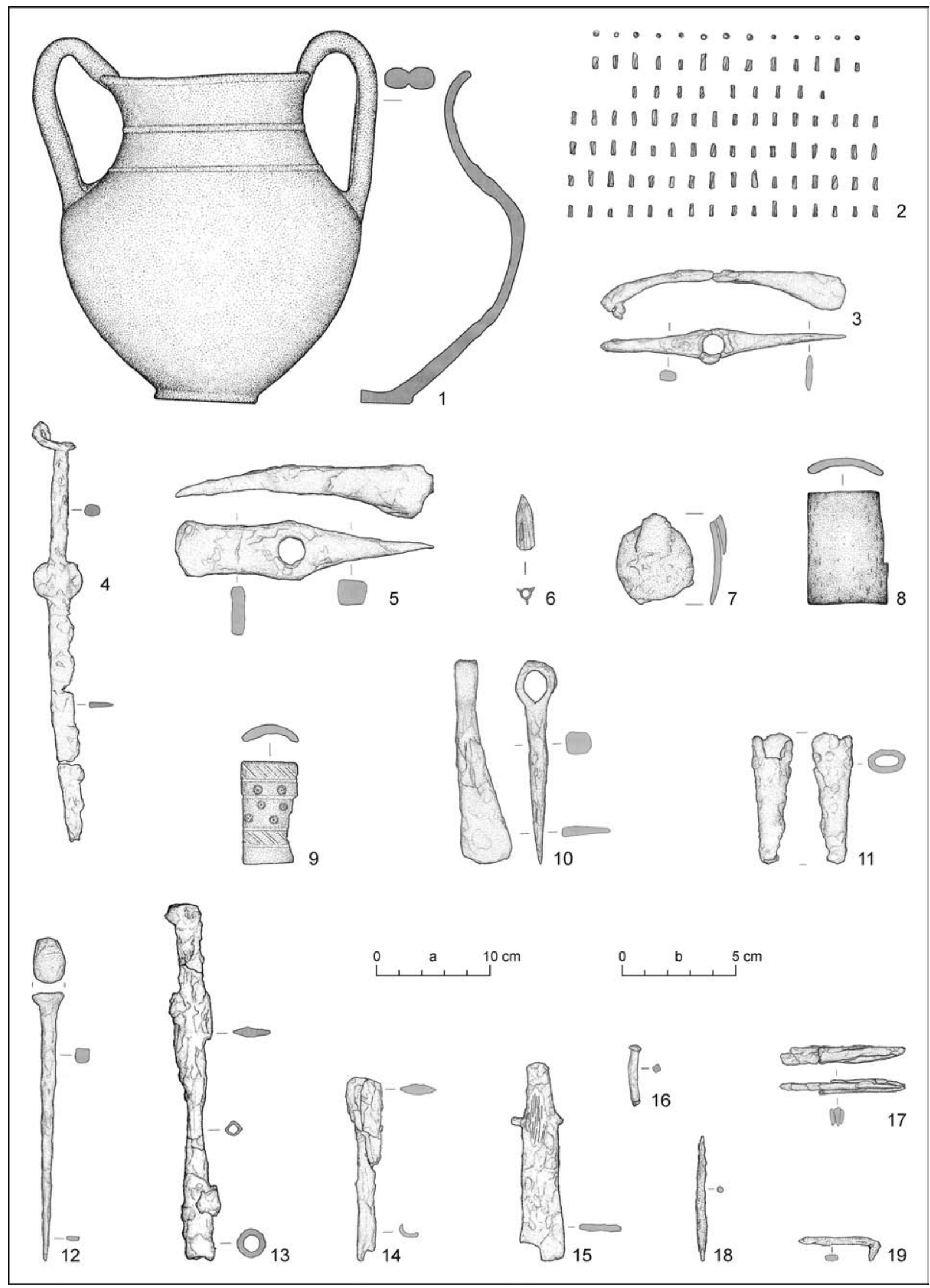

Abb. 6. Bátmonostor-Szurdok. Grabfunde (nach Gyucha u. a. 2015, Abb. 2-5). Maßstab: a - 1, 3-5, 10-17; b - 2, 6-9, 18, 19. 
von Hallstatt für die ganze Stufe HaD belegt sind und anhand des ersten Auftretens in der Stufe HaD1 zu den ältesten zählen, erscheinen die Klapprasiermesser in Ostslowenien erst in der Stufe HaD3 und sind hauptsächlich für das Fundgut der nachfolgenden Stufe LTA typisch. In der VK scheint ihr Vorkommen vor allem auf die Stufe HaD2 beschränkt zu sein, in HaD3 treten sie nur sporadisch auf. Für die Rasiermesser der VK besonders charakteristisch ist eine Kreisaugenverzierung, die mitunter mit Linien kombiniert ist, andere Motive, wie z. B. Gittermuster, kommen selten vor. Den ostslowenischen Exemplaren ist eine kombinierte Verzierung aus Kreisaugen, schraffierten Dreiecken und Gittermuster gemeinsam. Die Rasiermesser von Hallstatt ähneln mit ihrer Verzierung mehr den Vekerzuger Fundstücken als denjenigen aus Ostslowenien und zudem stehen sich die Exemplare aus der VK und der Nekropole von Hallstatt auch chronologisch nahe. Deshalb ist es anzunehmen, dass das Auftreten der Rasiermesser in der VK mit Einflüssen oder sogar Kontakten zum Inn-Salzach-Raum eng zusammenhängt (Kozubová 2012, 67-70).

\section{Zylindrische Gegenstände}

Die nicht zahlreichen, aber für den Formenschatz der VK besonders typischen ungleich großen, hohlen zylindrischen Gegenstände aus Geweih bzw. Knochen lassen sich vor allem anhand der andersartig angebrachten Löcher sowie abweichenden Befunde in drei Gruppen unterteilen, die zugleich wohl zu unterschiedlichen Zwecken benutzt wurden.

Der ersten Gruppe sind solche Zylinder zuzuordnen, für welche ihre häufige Vergesellschaftung mit Tonstempeln, Steinplatten, Miniaturgefässen und Stücken von anorganischen Farbstoffen eine Interpretation als Behälter zur Aufbewahrung von kosmetischen Mitteln zulässt. Die betreffenden Funde liegen zusammenfassend von J. Kisfaludi (1997, 79 f.) vor, ${ }^{27}$ ergänzt durch A. Kozubová (2013a, 134 ff.). Formenkundlich sind zylindrische Behälter einheitlich, sind kurz und breiter als andere zylindrische Artefakte, haben meistens zwei einander gegenüberliegende winzige Löcher bei einem der Ränder, wohl zur Befestigung des aus einem anderen organischen Material hergestellten Bodens, und unterscheiden sich voneinander nur durch die Ausmaße und noch dadurch, ob sie geometrisch verziert (Typ I) oder unverziert sind (Typ II). Die Ritzverzierung besteht aus verschiedenen Linien, einschließlich der einfachen oder mehrfachen Zickzacklinien, oder Horizontalbändern entweder aus schraffierten Dreieckern, leeren und schraffierten Rauten oder aus Gittermuster, wobei diese Verzierungselemente oft mit Kreisaugen kombiniert sind (Abb. 7: 6; Kisfaludi 1997, Abb. 13: 2-5; 14: 1-4; 15: 4-6). Alle Verzierungsmotive weisen zahlreiche Entsprechungen auf den Rasiermesserfunden, knöchernen Griffauflagen der Arbeits- und Streitmesser sowie Bestandteilen der Reitpeitschen aus Geweih und Knochen auf. Eine Konzentration von zylindrischen Behältern wurde auf dem Gräberfeld von Tápiószele festgestellt (Kisfaludi 1997, Abb. 13: 2, 3, 5; 14: 1, 2, 4; 15: 6; Párducz 1966).

Die Geweih-/Knochenzylinder der ersten Gruppe sind zwischen Oberösterreich und Ostungarn verbreitet, wo sich wie im Falle der Rasiermesser drei Verbreitungsschwerpunkte zeigen - in der VK, in der unterkrainischen Gruppe der Osthallstattkultur mit einer Anhäufung auf dem Gräberfeld von Magdalenska gora und auf dem Gräberfeld von Hallstatt (Kromer 1959, Taf. 121: 14; Tecco Hvala/Dular/Kocuvan 2004, Taf. 20D: 3, 4; 65C: 4; 84: 14, 15; 130A: 16, 17; 134D: 11). Im Rahmen dieser Hauptverbreitung erweisen sich gewisse Unterschiede, die sowohl in der Auswahl bzw. Bevorzugung einzelner Verzierungsmotive als auch in der Datierung der Zylinder zum Ausdruck kommen. Das Exemplar aus dem Grab 624 von Hallstatt ist nur rahmenhaft in die Stufen HaD1 und HaD2 einzuordnen, in Ostslowenien sind die solche Behälter dagegen für das Fundgut der Stufen HaD3 und LTA typisch. Das Stück aus der Bestattung 12 im Grabhügel 2 von Magdalenska gora scheint etwas älter zu sein und lässt sich aufgrund der Beifunde rahmenhaft nach HaD1-HaD2 datieren. In der VK sind zylindrische Behälter im Laufe des ganzen HaD hauptsächlich in den Inventaren reicher Frauenbestattungen nachweisbar, wobei den Frauen nur ein Exemplar beigegeben wurde. ${ }^{28}$ In den Frauengräbern von Magdalenska gora finden sich dagegen gewöhnlich zwei Stücke, die bezüglich ihrer Machart und Verzierung fast identisch sind. Das älteste

\footnotetext{
27 Die Fundliste bei Z. Kisfaludi kann um folgende Fundstücke ergänzt werden: BG 26/52 von Chotín IA und wohl auch BG 9 von Nové Zámky, BG 174 von Tiszalök-Börtön und Ždaňa. Bronzene Klapselanhänger von Hortobágy-Árkus und Szabadszállás-Józan mussen aus ihrer Liste hingegen entfernt werden (Kisfaludi 1997, 88, 93; Kozubová 2013b, Taf. 8: 3; Miroššayová 2015, 85, Taf. XXXV: 1; Scholtz 2010, 78, Taf. 5: 3; Stegmann-Rajtár 2009, Taf. 2: 8).

28 Eine Ausnahme ist das Brandgrab 113 von Tápiószele-Szumrák, wo zwei Behälter lagen (Kisfaludi 1997, 98, Abb. 13: 2, 3).
} 


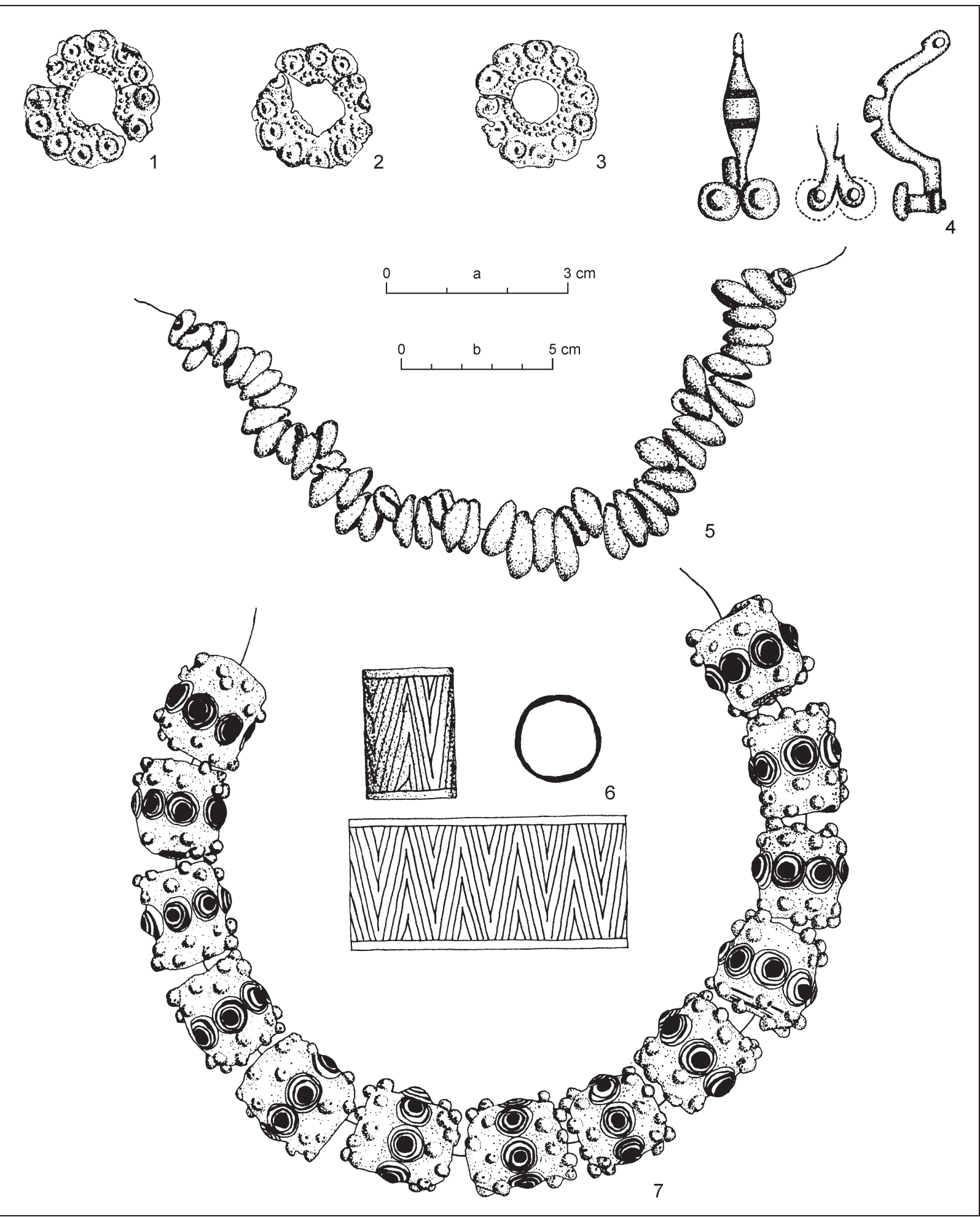

Abb. 7. Mezőtúr-Újváros. Grabfunde (nach Kisfaludi 1983, Abb. 1). Maßstab: a - 1-5, 7; b - 6.

Exemplar in der VK stellt der Zylinder aus dem Brandgrab 314 von Tápiószele wohl aus der beginnenden Stufe HaD1 dar, das jüngste ist dagegen das Stück von Mezőtúr-Újváros aus HaD3 (Abb. 7; Kozubová $2013 a, 134$ ff.). Ein weiteres, im Osten ganz isoliertes Exemplar wurde im Grabhügel 8 von Spasivka in der Westpodolien-Kultur gefunden, das nicht nur den östlichsten Fundpunkt in der Verbreitung der zylindrischen Behälter, sondern anhand der zeitlichen Einordnung des Grabinventars nicht später als in die 


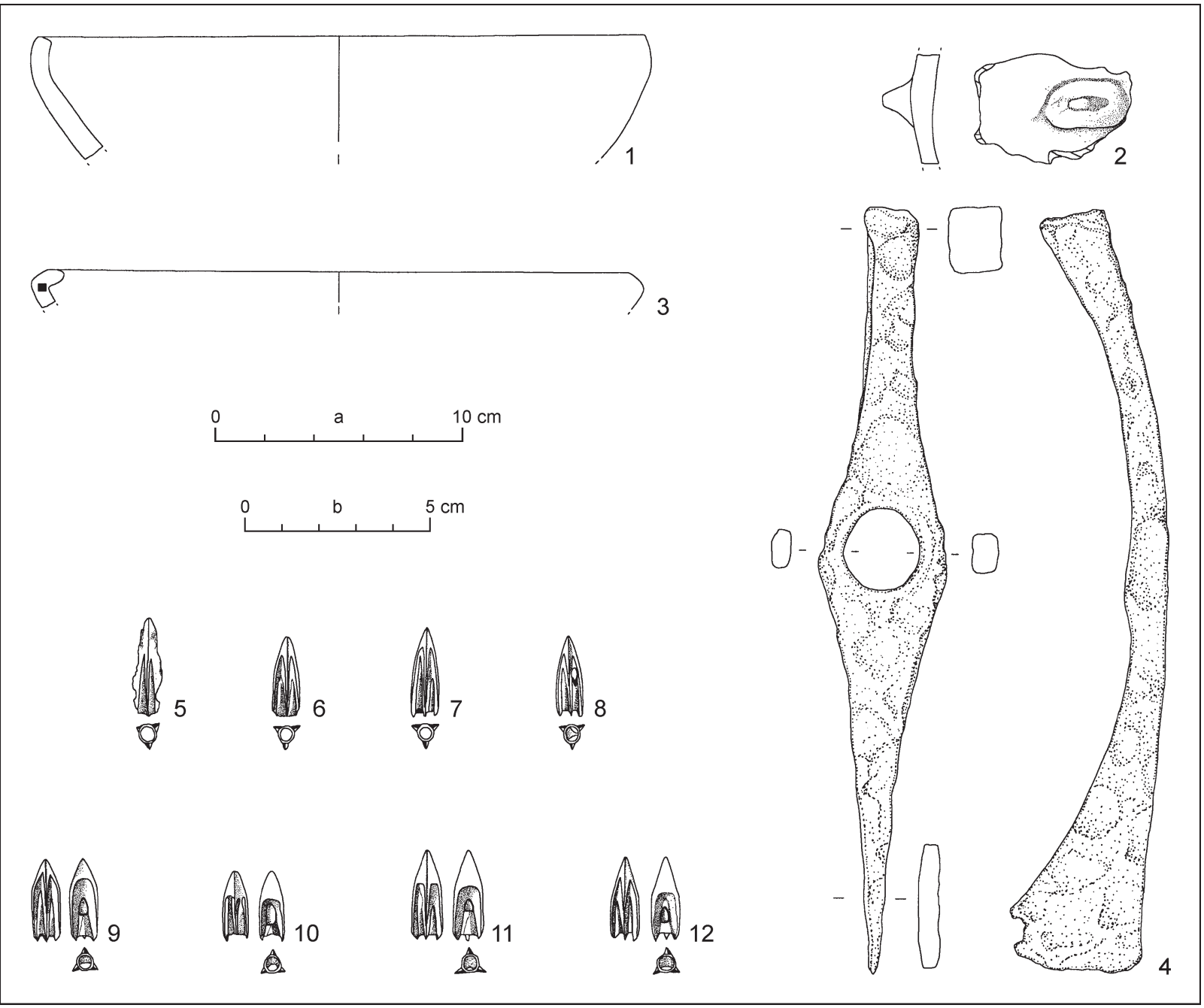

Abb. 8. Chotín IB. Körpergrab 49/61 (nach Kozubová 2013b, Taf. 102). Maßstab: a - 1-3; b-4-12.

Mitte des 7. Jhs. v. Chr. auch das älteste Fundstück darstellt. ${ }^{29}$ Nach der Verzierung steht der ukrainische Zylinder aber denjenigen von Magdalenska gora näher als den Funden der VK (Mogilov/Gucal/Gucal 2016, 228, Abb. 13: 1).

Die Exemplare der zweiten Gruppe zeichnen sich durch eine relativ lange und schmale Form aus, wobei ein der Enden meistens wenig verjüngt oder verstärkt ist. Zwei einander gegenüberliegende Löcher sind am Gegenstand gewöhnlich in seinem Mittelteil angebracht. Diese Zylinder unterscheiden sich von den obigen Behältern auch durch ihre Befunde, weil sie aus den reichen Waffen- und Pferdegeschirrgräbern mit männlichen Personen stammen (Kozubová 2008, 75, 78). ${ }^{30}$ Einige Fundstücke sind entweder geometrisch (Abb. 2: 8; 9: 1, 2) oder zoomorph verziert (Abb. 4: 9), unverzierte Exemplare sind aber auch vorhanden (Abb. 4: 10-12). Eine Sondergruppe bilden solche Gräber, wo zwei gleiche oder unterschiedliche Zylinder wohl als Bestandteil eines stabförmigen Gegenstandes vorkamen, wobei sie mittels der Niete an seinen beiden Enden befestigt wurden. Diese Annahme bestätigt auch der Befund im reichen Doppelgrab 16 von Csanytelek-Újhalastó, wo sich zwei nebeneinander liegende unterschiedlich ausge-

29 Ein weiterer kleiner Knochenzylinder mit einfacher Verzierung aus Kreisaugen kam im Grabhügel VI auf dem Gräberfeld von Trinca-Drumul Feteştilor im Zentralteil des Dnjeper-Pruth-Gebietes zutage. Das Gräberfeld ist rahmenhaft in die zweite Hälfte des 7. Jhs. und ins erste Viertel des 6. Jhs. v. Chr. datiert (Levițchi 2006, Abb. 31: 1-5, 8, 9; Levickij/Kašuba 2009, 257, 258).

30 KG von Cegléd-Hordógyár; KG 9 und 16 von Csanytelek-Újhalastó; Grab 2 von Hajdúnánás-Verestengerjárás; KG 49/61 von Chotín IB (Abb. 8), BG 320 von Tiszalök-Börtön (Fodor 2015, Abb. 3; Galántha 1981, 50, 54, Abb. 8; 9: 6, 7; 12: 6; Kemenczei 1986, 118, 122, Abb. 4: 3, 4; Kozubová 2013b, Taf. 103: 1, 1a, 2, 2b; Scholtz 2006, 58, Abb. 5: 3). 


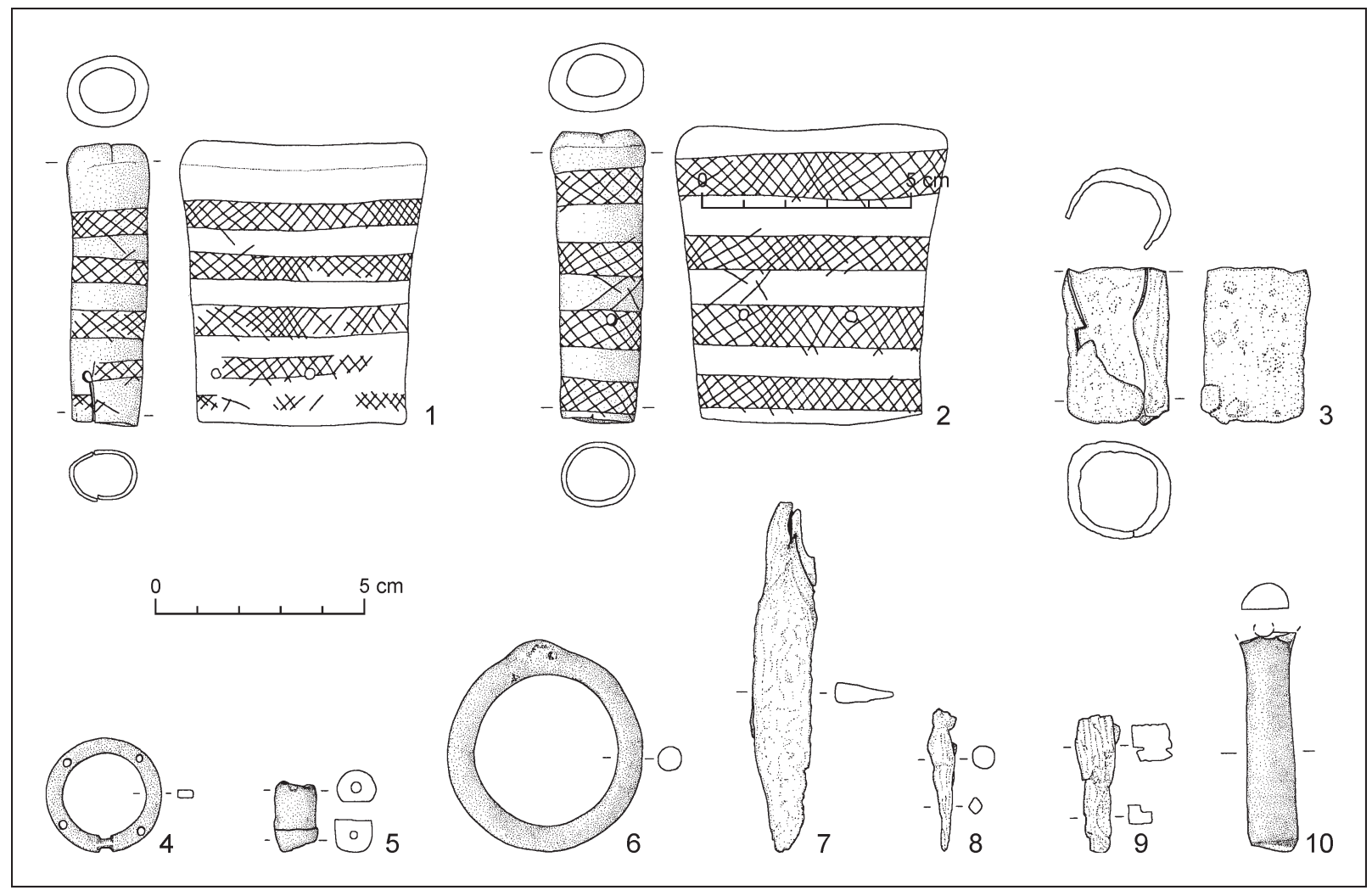

Abb. 9. Chotín IB. Körpergrab 49/61. Fortsetzung (nach Kozubová 2013b, Taf. 103).

arbeitete Zylinder beim linken Oberarm eines der bestatteten Kinder befinden (Galántha 1986, 50, Abb. 8: 11, 12; 9: 6, 7). Diese Fundlage deutet ein Vorhandensein von einem nicht mehr als $30 \mathrm{~cm}$ langen stabförmigen Gegenstand aus organischem Material im Grab an, der an beiden Enden mit knöchernen Teilen versehen war. Wegen der fehlenden oder alten Befundüberlieferungen sowie häufigen Zerstörung ist die ursprüngliche Fundlage der Zylinder in übrigen Gräbern leider nicht bekannt. Anhand der formenkundlichen, aber nicht zahlreichen Parallelen im eisenzeitlichen Fundmaterial aus Eurasien erweist sich die Verwendung der zylindrischen Gegenstände der zweiten Gruppe als Bestandteile von Reitpeitschen als sehr wahrscheinlich (dazu siehe Kozubová 2008). Auch eine andere Funktionszuweisung, wie z. B. als Teile eines Kultstabes, lässt sich jedoch nicht ausschliessen.

Die zylindrischen Gegenstände der dritten Gruppe ähneln formenkundlich denjenigen aus der zweiten Gruppe, ihre Befunde sind aber unterschiedlich. Sie liegen entweder aus den Frauenbestattungen ${ }^{31}$ oder aus waffen- und pferdegeschirrlosen Gräbern von Männern vor (Abb. 10: 4). Eine Ausnahme sind zwei unvollständig erhaltene Geweihzylinder ohne Löchern aus dem Waffengrab von BátmonostorSzurdok, die anhand der Ausmaße und fehlenden Löcher den Zylindern der ersten Gruppe zuzuweisen sind und so ein weibliches Element im Grabinventar darstellen könnten (Abb. 6: 8, 9).

\section{Schmuck}

Unter den Schmuckstücken aus Tierknochen, die fast alle aus Gräbern stammen, ${ }^{32}$ finden sich typologich wenig variable Perlen, seltene Anhänger und relativ zahlreiche, gelochte Zähne. Anhand der Angaben zur Trageweise einiger Perlen können diese Bestandteil nicht nur einer Halskette, sondern

31 BG 174 von Tiszalök-Börtön (Scholtz 2010, 78, Taf. 5: 2).

32 Das Siedlungsobjekt 15 von Gyulavári lieferte eine schmale zylindrische Knochenperle, eine durchbohrte Bärenkralle kam dagegen im Siedlungsobjekt 123 von Ludányhalászi-Sóderbánya vor. Vier Knochenperlen und wahrscheinlich ein scheibenförmiger Anhänger stammen aus dem Siedlung von Vel'ký Cetín-Pilišské (Gyucha 2002, 62, Abb. 10: 5; Cheben/Ruttkayovál Ruttkay 1994, 182 f., Abb. 18: 2, 6, 11; Tugya 2010, 361, Abb. 2: 3). 


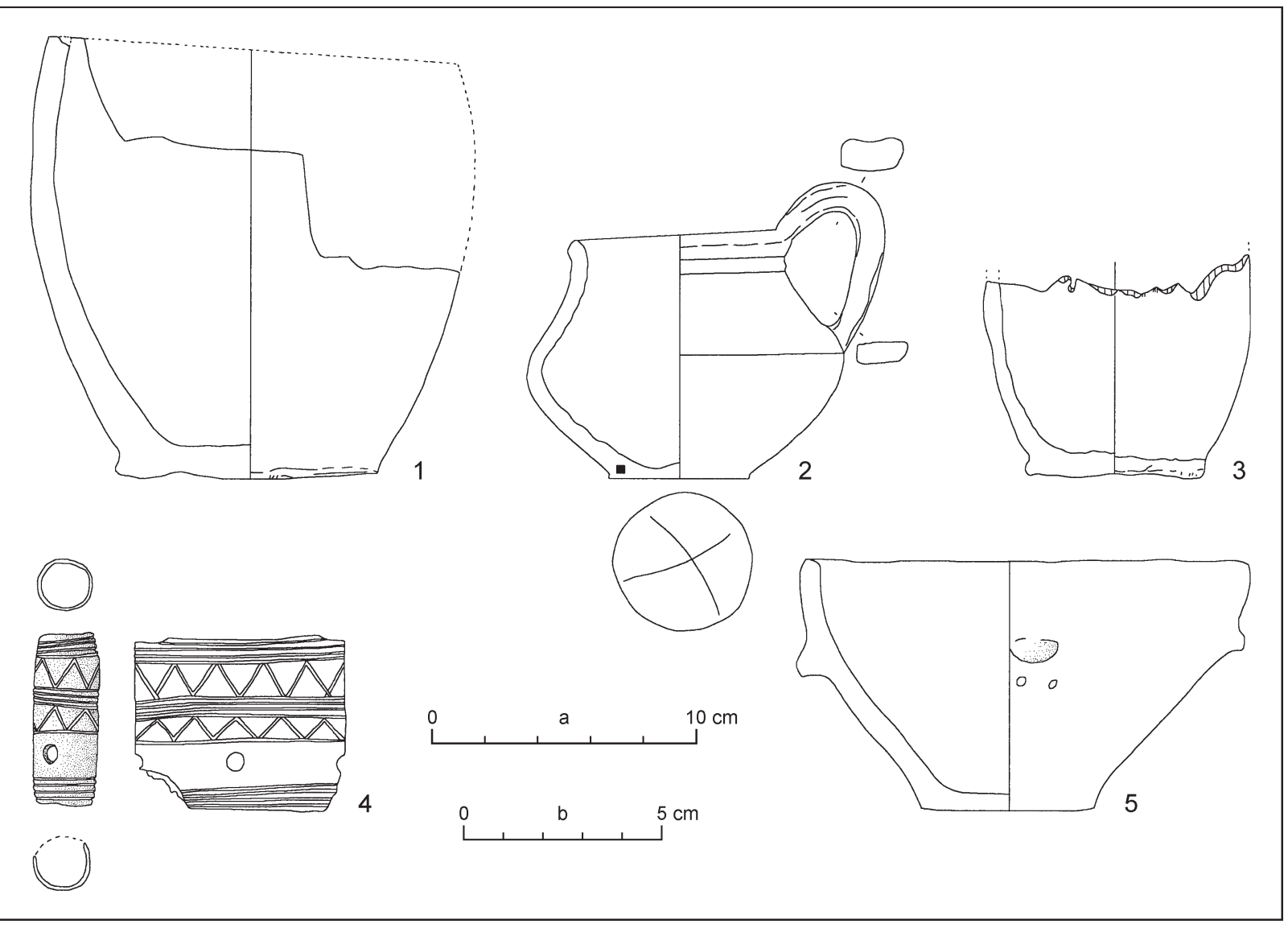

Abb. 10. Chotín IA. Körpergrab 143/53 (nach Kozubová 2013b, Taf. 55: 9-13). Maßstab: a - 1-3, 5; b - 4.

auch eines aus verschiedenen Komponenten zusammengesetzten Armringes gewesen sein. Im Körpergrab 173 von Tiszalök-Börtön lag eine schmale zylindrische Knochenperle senkrecht zur Innenseite des linken Unterarmes einer erwachsenen Frau, deren einfache Schmucktracht zusätzlich aus einem gelochten und neben linker Hand gefundenen Hirschzahn bestand (Scholtz 2012, 78, Taf. 4: 1, 6, 8). Als weiteres seltenes Beispiel für die mögliche Verwendung von Knochenperlen als Armschmuck ist das Körpergrab 2 von Szentes-Vekerzug zu nennen, wo sich zwei zylindrische Exemplare beim rechten Handgelenk eines erwachsenen Mannes befanden (Csallány/Párducz 1944-1945, 106, Taf. XLII: 15, 16). Mehrere Perlen wurden in Brandgräbern gefunden oder sind ohne verlässliche Befundbeobachtungen oder blieben bislang umfassend unpubliziert und lassen daher keine Rückschlüsse auf die genaue Verwendung dieser Stücke als Hals- oder Armschmuck zu. ${ }^{33}$ Solche Exemplare, die hier als Perlen zusammengefasst sind, dürften im Falle ihrer Vergesellschaftung mit Perlen aus anderen Materialien vor allem in Verbindung mit Halsketten zu sehen sein, es ist aber nicht ausgeschlossen, dass im Grab allein vorkommende Stücke ohne andere Perlentypen als Anhänger oder Amulette verwendet wurden (z. B. Körpergrab 8 von Szentes-Vekerzug; Csallány/Párducz 1944-1945, 107, Taf. XLVI: 1). Entsprechend vielseitig konnte auch die Verwendung von gelochten Tierzähnen sein, die meistens einzeln oder seltener kombiniert mit anderen Perlentypen um den Hals getragen wurden. Der Knochenschmuck beschränkt sich auf unterschiedlich große Perlen, die meistens zu Zylindern, vereinzelt auch zu unverzierten rechteckigen und ovalen Plättchen mit einer Durchlochung im Mittelteil (Abb. 11: 1) ${ }^{34}$ oder

33 BG 44, 110 von Alsótelekes-Dolinka; Gräberfeld von Branč; BG 1 von Dédestapolcsány-Verebce-tető; Grab 2 von HajdúnánásVerestengerjárás; BG 12 von Kesznyéten-Szérűskert; KG 8, 17 von Nyáregyháza; BG 48 von Tiszavasvári-Csárdapart (Fodor 2015, 123; F. Tóth 2012, 63, Taf. 3: 21; Hečková 1986, 99; Kemenczei 2001-2002, 47, Abb. 13: 13; 2009, 157; Kisfaludi 2004, 168, Taf. VII: 8; IX: 6; Patay 1961, 34, Taf. VII: 26-28; Patay/B. Kiss 2001-2002, 83, Abb. 8: 1, 2).

34 BG 44, 110 von Alsótelekes-Dolinka; BG 1 von Dédestapolcsány-Verebce-tető; KG 8 von Nyáregyháza (F. Tóth 2012, 63, Taf. 3: 21; Kisfaludi 2004, 168, Taf. VII: 8; Patay 1961, 34, Taf. VII: 26, 27; Patay/B. Kiss 2001-2002, 83, Abb. 8: 1, 2). 


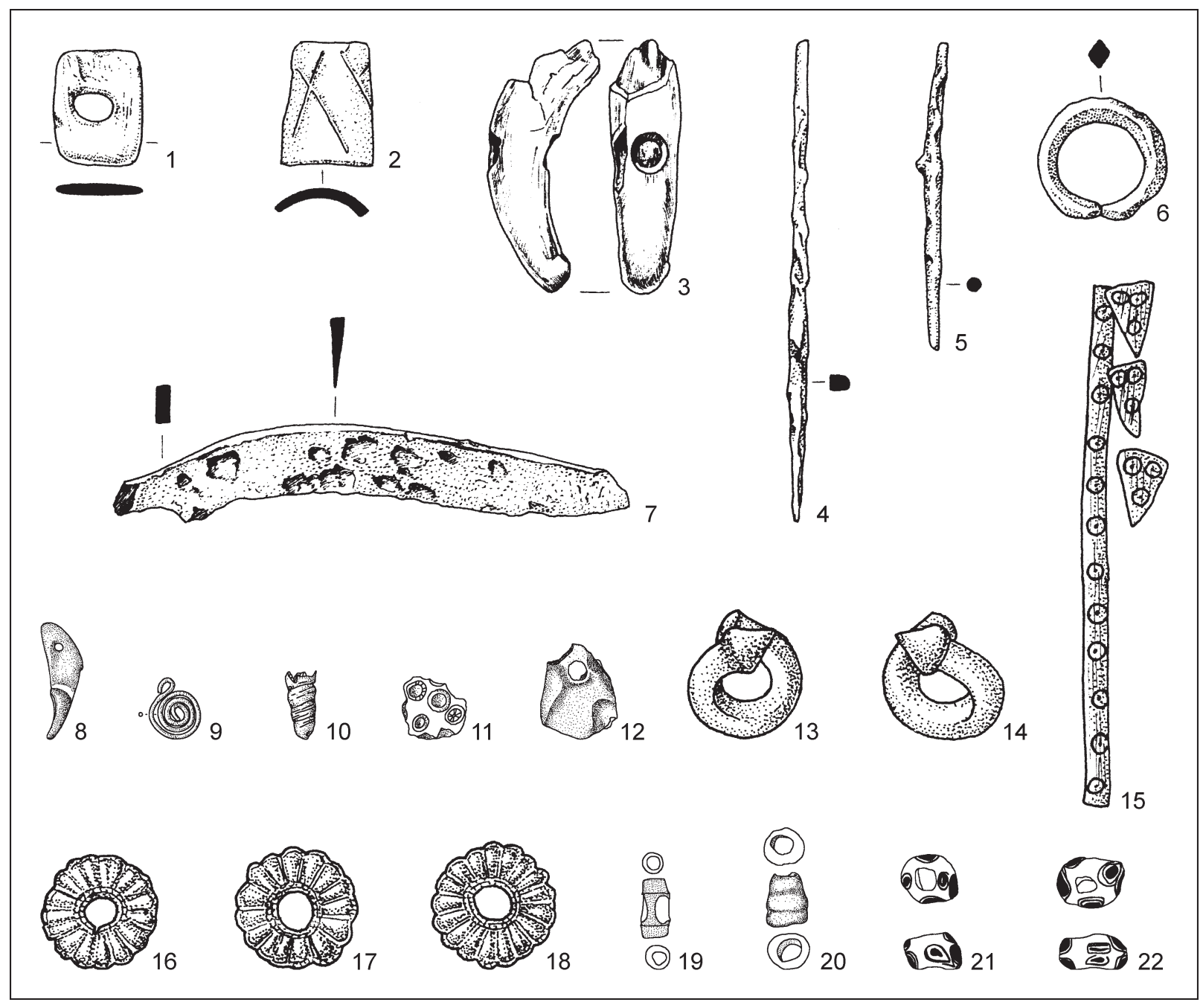

Abb. 11. Schmuck aus Knochen/Geweih und Tierzähnen aus den Fundstellen der Vekerzug-Kultur. 1-7 - Alsótelekes-Dolinka, Brandgrab 110 (nach Patay/B. Kiss 2001-2002, Abb. 8: 1-4, 6-8); 8-12 - Chotín IA, Körpergrab 285/54 (nach Kozubová 2013b, Taf. 88: 18-22); 13-18 - Csárdaszállás-Hanzélitanya, Brandgrab 22 (nach Kemenczei 2001-2002, Abb. 4: 18-23); 19-22 - Chotín IA, Körpergrab 115/53 (nach Kozubová 2013b, Taf. 49: 14-17). Verschiedene Maßstäbe.

zu winzigen Kügelchen und Ringen ${ }^{35}$ geschnitten wurden (Kozubová 2013a, 45, 47, Anmerkung 70). Die meisten zylindrischen Perlen sind unverziert, ${ }^{36}$ einige große Exemplare sind mit einfacher geometrischer Verzierung in Form von verschiedenen Linien oder Kerben versehen (Abb. 11: 2, 20). ${ }^{37}$ Die Knochenperlen sind in der Regel mit Glas-, Ton- und Bernsteinperlen kombiniert und wurden gelegentlich auch durch bronzene Spiralröllchen und Ringelchen sowie Tierzähne und Kaurischnecken ergänzt (z. B. Körpergrab 111/53 von Chotín IA; Kozubová 2013b, 60 f., Taf. 48: 10, 16-19, 32-67). Solche Halsketten scheinen von Kindern, Jugendlichen und Frauen getragen worden zu sein, einzeln auftretende Knochenperlen liegen hingegen auch aus den Männerbestattungen vor (z. B. Körpergrab 8 von Szentes-Vekerzug; Csallány/Párducz 1944-1945, 107, Taf. XLVI: 1). Im Unterschied zu Ton-, Glas- oder Bernsteinperlen kommen die Knochenperlen entweder nur einzeln oder in zwei Exemplaren in den Gräbern vor.

35 KG 17 von Nyáregyháza; BG 48 von Tiszavasvári-Csárdapart (Kemenczei 2009, 157; Kisfaludi 2004, 169, Taf. IX: 6).

36 KG 5 von Békéscaba-Fényes; SO 15 von Gyulavári; KG 111/53, 115/53, 200/54 von Chotín IA; BG 12 von Kesznyéten-Szérűskert; KG 43 von Nyáregyháza; KG 2, 8 von Szentes-Vekerzug; KG 173 von Tiszalök-Börtön (Csallány/Párducz 1944-1945, 106 f., Taf. XLII: 15; XLVI: 1; Gyucha 2002, 62, Abb. 10: 5; Kemenczei 2001-2002, 47, Abb. 13: 13; Kisfaludi 2004, 173, Taf. XV: 12; Kozubová 2013b, 60 ff., 89, Taf. 48: 19; 49: 17; 72: 3; Párducz 1943, Taf. VIII: 5, 6; Scholtz 2012, 78, Taf. 4: 6).

37 BG 110 von Alsótelekes-Dolinka; KG 2 von Szentes-Vekerzug (Csallány/Párducz 1944-1945, 106, Taf. XLII: 16; Patay/B. Kiss 2001-2002, 83, Abb. 8: 2). 
In der VK wurden Hunde-, Wolfs-, Bären-, Pferde- und Hirschzähne, sporadisch auch Haus- oder Wildschweinhauer und Bärenkrallen insbesondere als Brustanhänger oder Bestandteile der Halsketten und höchst selten auch als Armschmuck ${ }^{38}$ verwendet (Abb. 11: 3; Kemenczei 2009, 186; Kisfaludi 2004, 169; Kmetová 2014, 131 f., Abb. 30; Kozubová 2013a, 54 f., Anmerkung 95; Tugya 2010, 361, Abb. 2: 3). ${ }^{39}$ Die Trachtlage eines durchlochten Wolfszahnes im Beckenbereich des erwachsenen Mannes aus dem Körpergrab 2 von Szentes-Vekerzug könnte hingegen auf eine Verwendung als Gehänge eines aus organischem Material hergestellten Gürtels hinweisen (Csallány/Párducz 1944-1945, 106, Taf. XLII: 10). Durchbohrte Tierzähne verschiedener Varianten waren im Laufe der ganzen Eisenzeit weit in Mittel- und Osteuropa als multifunktionale Objekte - Brustanhänger, Amulette, Bestandteile der Halsketten, Ohrring- und Halsringanhänger, Pferdegeschirrbestandteile - verbreitet und sind daher kulturell unspezifisch (Ilinskaja 1968; Kozubová 2011, 91 f.; Petrenko 1978; Stöllner 2002, 77) In der VK sind die Zahnanhänger aber nicht so beliebt wie in Osteuropa.

Wohl als Anhänger mit apotropäischem Charakter können ein durchlochtes Schädelfragment von einem Hausschwein aus dem Körpergrab 285/54 von Chotín IA und ein flacher spinnwirtelförmiger Gegenstand aus Schafbein aus dem Brandgrab 4 von Dédestapolcsány-Verebce-tető betrachtet werden, wobei in beiden Gräbern kleine Kinder bestattet waren. Chotíner Exemplar war zudem mit einem Hundezahn, Fischwirbel, bronzenen Brillenanhänger und einer Turritella-Schnecke vergesellschaftet (Abb. 11: 8-12; F. Tóth 2012, 64, Taf. 8: 3; Kozubová 2013b, 112 f., Taf. 88: 18-22). Aus drei Körpergräbern von Chotín IA stammen mehrere gelochte Fischwirbel (Flussfische) als Hals- und Armringschmuck (Kozubová 2013b, 47, 83 f., 115, Abb. 126; 240; 354; Taf. 38: 8-12; 68: 99).

Trotz der leichten Beschaffbarkeit des Rohmaterials spielten Knochenperlen und -anhänger sowie gelochte Zähne in den Schmucktrachten der VK eine unbedeutende Rolle, wobei sie bei Frauen und Kindern beliebter als bei Männern waren. Chronologisch ist Knochenschmuck in der VK ohne Relevanz, weil dieser während ihrer ganzen Existenz auftrat.

\section{Sonstige Gegenstände}

Dieser Fundkategorie wurden alle Gegenstände ohne eindeutige Funktion oder mit möglicher Multifunktionalität zugerechnet, wie auch solche Artefakte, die mit keiner der oben behandelten Fundgruppen in Zusammenhang stehen. Aus dem Siedlungsobjekt 101/77 von Chotín VII stammt ein Schlittschuhfund, ein weiteres Exemplar aus Pferdeknochen ist aus dem Siedlung von LudányhalásziSóderbánya bekannt (Romsauer/Hečková/Repka 2019, 211 ff., Taf. XXIII: 7; Tugya 2010, 361, Abb. 2: 6). Ohne nähere Vergleiche bleibt ein knöcherner Gegenstand in Form der Ahle von Szurdokpüspöki mit einem sehr schematisierten Adlerkopfende, dessen Verwendung als Ahle oder Griffauflage eines Messers aber sehr unwahrscheinlich ist (Tankó 2015, 435, Abb. 3: 1). In den Beigaben einiger Brandbestattungen fanden sich sehr schmale und ungleich lange knöcherne Plättchen mit Kreisaugenverzierung, die entweder zur Verkleidung eines aus organischem Material (Holz) hergestellten Behälters benutzt werden konnten oder ursprünglich Bestandteil eines fragmentiert erhaltenen Gegenstandes waren (Abb. 11: 15). ${ }^{40}$ Ähnliche Verwendungsmöglichkeiten sind im Falle der plattenförmigen Fragmente mit geritzter Kreisaugen- und Mäanderverzierung aus dem HaD1-zeitlichen Grab 2 von Tarnabod-Téglásdomb anzunehmen, zu denen sich gute Vergleiche im "Grabhügel“ von Regöly bieten (Párducz 1969, Taf. III: 18-22; Szabó/Fekete 2014, Taf. $1 ; 9 ; 114 ; 123)$.

38 Z. B. KG 173 von Tiszalök-Börtön (Scholtz 2012, 78, Taf. 4: 1, 8).

39 Relativ zahlreich sind Tierzähne auf den Gräberfeldern von Chotín IA und Tápiószele-Szumrák vertreten (Kozubová 2013b, 38, 60 f., 84, 102, 112 f., Taf. 30: 5, 8; 48: 10; 67: 11; 81: 14; 88: 18; Párducz 1966, 48, 51, 53, 60, 63, 67, 74, 77 ff., Taf. XXII: 4-10; XXXIX: 32, 35; LI: 1; LXVI: 4; LIII: 19; LXXI: 15, 16; LXXII: 7).

40 BG 22 von Csárdaszállás-Hanzélitanya; BG 140 von Orosháza-Gyopáros; BG 31 von Szentes-Vekerzug; BG 126 von Tápiószele-Szumrák (Juhász 1976, 248, Abb. 8: 4; Kemenczei 2001-2002, 33, Abb. 4: 18; Párducz 1954, 31, Taf. IV: 1-6; 1966, 48, Taf. XXI: 4-11). 


\section{ZUSAMMENFASSUNG}

Knochen-, Geweih- und Zahnartefakte bilden in der VK zwar eine nicht so zahlenmäßig große Fundgruppe wie Keramikgefäße oder Schmuck, Waffen und Geräte/Werkzeuge aus Metallen, sie repräsentieren jedoch einen der interessantesten Bestandteile ihrer Formenwelt. Die meisten von ihnen stammen aus Grabinventaren, Siedlungsfunde sind überraschend deutlich seltener. Einige Fundtypen aus Geweih/Knochen, wie z. B. dekorative Köcherteile, zylindrische Gegenstände aller Art, eiserne Messer mit verzierter Griffauflage sowie Klapprasiermesser, dienen in der VK zusammen mit Waffen, Pferdegeschirr und Schmuck aus Metallen und anderen Materialen zur Visualisierung der sozialen Identitäten. Trotzdem sie relativ begrenzte chronologische Aussagekraft besitzen, belegen manche Artefakte aus Geweih und Knochen die über weite Distanzen reichenden Kulturbeziehungen der VK. Insbesondere verzierte Exemplare zeigen das relativ hohe technische Niveau in der Knochen- und Geweihbearbeitung. Da fast alle Keramikgefäße unverziert sind, bilden relativ häufige geometrische und zoomorphe Motive auf manchen Knochen- und Geweihartefakten sowie auf metallischen Waffen und Pferdegeschirrbestandteilen die grundlegende Quelle für die Rückschlüsse auf die Geisteshaltung der Bevölkerung der VK.

Aus Geweih und Knochen wurden in der VK meistens funktional wohl unterschiedliche zylindrische Gegenstände sowie Griffauflagen der Arbeits- bzw. Streitmesser hergestellt, andere Fundkategorien wie Waffen und Zubehör, Pferdegeschirr, Geräte und Werkzeuge sowie Schmuck sind weniger zahlreich.

Im Fundgut der VK sind solche Fundtypen aus Knochen und Geweih vertreten, die sowohl lokal begrenzt sind, als auch relativ weite Verbreitungsgebiete aufweisen. Der ersten Gruppe sind vor allem zylindrische Gegenstände, der zweiten Gruppe wohl Bestandteile von Reitpeitschen, eiserne Arbeit- und Streitmesser mit geometrisch und zoomorphisch verzierter Griffauflage, zoomorph dekorative und kreuzförmige Köcherteile sowie einige zoomorphe Darstellungen (Pferdeköpfe) zuzuordnen, die außerhalb der VK eher zu Ausnahmefunden gehören. Zur zweiten Gruppe zählen solche Artefakte, für welche sich gute Vergleiche im Formenschatz der benachbarten Kulturen und Kulturgruppen bieten, und zwar in der Osthallstattkultur, wie z. B. zweiteilige Rasiermesser, zylindrische Behälter, einige Riemenzierrate (Ringfuß- und Quadratfußknöpfe) oder geometrische Verzierungselemente, und im Waldsteppengebiet Osteuropas und im Nordkaukasus, wie z. B. Knochenpfeilspitzen, zoomorphe Knebel, einige Riemenzierrate (zylindrische Riemenverteiler) und einige zoomorphe Darstellungen (Adlerköpfe). Die ausführliche Analyse der Knochen-, Geweih- und Zahnartefakte bestätigt zudem die bisherigen Untersuchungen zur VK und zeigt klar, dass in ihrem Fundgut keine Einflüsse aus dem osteuropäischen Steppengebiet vorhanden sind und daher gibt es keine Gründe dafür, die VK als skythisch, skythoid oder sogar skythisch geprägt zu bezeichnen. Auch der gesamte Charakter der östlichen Beziehungen macht es nicht möglich, die VK den östlichen Kulturen zuzuordnen (Kozubová 2019a).

\section{LITERATUR}

Benadik 1983

Csallány/Párducz 1944-1945

Cseh 2006

Czifra u. a. 2017

Dušek 1966

F. Tot 2015

F. Tóth 2012

Farkaš 1986
B. Benadik: Maňa. Keltisches Gräberfeld. Fundkatalog. Materialia Archaeologica Slovaca V. Nitra 1983.

G. Csallány/M. Párducz: Szkítakori leletek a szentesi múzeumban. Archaeologiai Értesitő 3, 1944-1945, 81-117.

J. Cseh: Archaeologia Scythica. Adalékok a Közép-Tisza mente vaskori történetéhez. Tisicum 15, 2006, 13-42.

S. Czifra/M. Kreiter/É. Kovács-Széles/M. Tóth/O. Viktorik/B. Tugya: Scythian age settlement near Nagytarcsa. Acta Archaeologica Academiae Scientiarum Hungaricae 68, 2017, 241-298.

M. Dušek: Thrakisches Gräberfeld der Hallstattzeit in Chotín. Archeologica Slovaca VI. Bratislava 1966.

M. F. Tot: Zoomorfnyj psalij skifskogo vremeni iz roga olenja s poselenija v Srednem Potis'e v Vengrii. Stratum plus 3, 2015, 297-306.

M. F. Tóth: Korai szkítakori sírok Dédestapolcsány-Verebce-tető lelőhelyen. A Hermann Ottó Múzeum Évkönyve 51, 2012, 63-91.

Z. Farkaš: Nález noža z doby halštatskej vo Vel'kom Grobe, okr. Galanta. Archeologiclé rozhledy 38, 1986, 168-175. 
Fodor 2015

Gabrovec u. a. 2006

Galanina 1997

Galántha 1981

Galántha 1985

Galántha 1986

Gyucha 2002

Gyucha u. а. 2015

Hânceanu 2019

Hečková 1986

Hellmuth 2006

Hencken 1978

Cheben/Ruttkayová/Ruttkay 1994

Chochorowski 1985

Ilinskaja 1968

Istuánovits 1997

Juhász 1972

Juhász 1976

Kalicz/Koós 1998

Kemenczei 1986

Kemenczei 2001-2002

Kemenczei 2005

Kemenczei 2009

Kisfaludi 1983

Kisfaludi 1997

Kisfaludi 2004

Kmetová 2014

Knez 1986

Korol'kova 2006

Kovpanenko 1981

Kozubová 2008
I. Fodor: Skythenzeitliche Stabenden aus Bein von Hajdúnánás (Ungarn). In: I. Szathmári (Hrsg.): An der Grenze der Bronze- und Eisenzeit. Festschrift für Tibor Kemenczei zum 75. Geburtstag. Budapest 2015, 121-128.

S. Gabrovec/A. Kruh/I. Murgelj/B. Teržan: Stična II/1. Gomile starejše železne dobe. Katalog. Katalogi in monografije 37. Ljubljana 2006.

L. K. Galanina: Die Kurgane von Kelermes. Königsgräber der frühskythischen Zeit. Steppenvölker Eurasiens I. Moskau 1997.

M. Galántha: Előzetes jelentés a csanytelek-újhalastói szkíta kori temető ásatásáról. Communicationes Archaeologicae Hungaricae 1981, 1981, 43-58.

M. Galántha: Előzetes jelentés a Sándorfalva-Eperjesi szkíta kori temető feltárásáról. A Móra Ferenc Múzeum évkönyve 1982-1983, 1985, 115-128.

M. Galántha: The Scythian Age Cemetery at Csanytelek-Újhalastó. In: L. Török (ed.): Hallstatt Kolloquium Veszprém 1984. Budapest 1986, 69-77.

A. Gyucha: Újabb szkíta kori telepnyomok Békés megyéből. A Békés Megyei Múzeumok Közleményei 23, 2002, 59-88.

A. Gyucha/G. Gulyás/B. Török/P. Barkóczy/Á. Kovács: Connected regions, shared traditions: A unique Middle Iron Age burial from the Danube-Tisza Interfulve. In: I. Szathmári (Hrsg.): An der Grenze der Bronze- und Eisenzeit. Festschrift für Tibor Kemenczei zum 75. Geburtstag. Budapest 2015, 179-198.

G. D. Hânceanu: O aplică scitică de tolbă din corn descoperită în aşezarea de la Roşiori-Dulceşti (jud. Neamț). Revista Arheologică 15, 2019, 85-93.

J. Hečková: Nálezy z doby halštatskej z Branča. AVANS v roku 1985, 1986, 99.

A. Hellmuth: Untersuchungen zu den sogenannten skythischen Pfeilspitzen aus der befestigten Höhensiedlung von Smolenice-Molpir. Universitätsforschungen zur prähistorischen Archäologie 128. Bonn 2006.

H. Hencken: The Iron Age Cemetery of Magdalenska gora in Slovenia. Harvard 1978. I. Cheben/J. Ruttkayová/M. Ruttkay: Výskumy na trase ropovodu vo Vel'kom Cetíne. Študijné zvesti Aú SAV 30, 1994, 177-241.

J. Chochorowski: Die Vekerzug-Kultur. Charakteristik der Funde. Prace archeologiczne 36. Kraków 1985.

V. A. Ilinskaja: Skify Dneprovskogo lesostepnogo Levoberež ja. Kiev 1968.

E. Istvánovits: Nyíregyháza-Manda-bokor. Kora vaskori telepulés a Kr. e. VI-IV századból. In: P. Raczky/T. Kovács/S. Anders (eds.): Utak a múltba. az M-3-as autópálya régézet leletmentései. Budapest 1997, 75-80.

I. Juhász: Az Orosháza-gyopárosi szkítakori temető. Archaeologia Értesítő 99, 1972, 214-223.

I. Juhász: Az Orosháza-gyopárosi szkítakori temető. Archaeologia Értesítő 103, 1976, 231-252.

N. Kalicz/J. Koós: Siedlungsfunde der Früheisenzeit aus Nordostungarn. In: B. Hänsel/J. Machnik (Hrsg.): Das Karpatenbecken und die osteuropäische Steppe. Prähistorische Archäologie in Südosteuropa 12. München 1998, 423-436.

T. Kemenczei: Mitteleisenzeitliche Köcherbeschläge aus dem Alföld. Folia Archaeologica 37, 1986, 117-136.

T. Kemenczei: Beiträge zur Schmuckmode der Alföld-Gruppe skythischer Prägung. Folia Archaeologica 49-50, 2001-2002, 29-73.

T. Kemenczei: Zu den östlichen Beziehungen der skythenzeitlichen Alföld Gruppe. Communicationes Archaeologicae Hungariae 2005, 2005, 177-211.

T. Kemenczei: Studien zu den Denkmälern skythisch geprägter Alföld Gruppe. Inventaria Praehistorica Hungariae XII. Budapest 2009.

J. Kisfaludi: Szkíta sír Mezőtúrról. Archaeologiai Értesítő 110, 1983, 68-72.

J. Kisfaludi: Tonstempel und Knochenzylinder aus der mittleren Eisenzeit im Karpatenbecken. Communicationes Archaeologicae Hungariae 1997, 1997, 75-107.

J. Kisfaludi: Szkíta kori temető a Nyáregyháza M5-4 autópalya nyomvonalában. Studia Comitatensia 28, 2004, 167-198.

P. Kmetová: Deponovanie koní na pohrebiskách z doby halštatskej v priestore Panónskej panvy. Dissertationes Archaeologicae Bratislavenses 2. Bratislava 2014.

T. Knez: Novo mesto I. Halštatski grobovi. Carniola archaeologica 1. Novo mesto 1986

E. F. Korol'kova: Zverijnyj stil' Evrazii. Iskusstvo plemen Nižnego Povolž'ja i Južnogo Priuralja v skifskuju epochu (VII-IV vv. do n. e.). Sankt-Peterburg 2006.

G. T. Kovpanenko: Kurgany ranneskifskogo vremeni v bassejne r. Ros'. Kiev 1981.

A. Kozubová: Kostené valcovité predmety z pohrebísk vekerzugskej kultúry v severozápadnej časti Karpatskej kotliny. Zborník SNM 102. Archeológia 18, 2008, 49-94. 
Kozubová 2009

Kozubová 2011

Kozubová 2012

Kozubová $2013 a$

Kozubová $2013 b$

Kozubová 2019a

Kozubová $2019 b$

Kromer 1959

Kulatova/Lugovaja/Suprunenko 1993

Kuzma 2011

Leszih 1939

Levickij/Kašuba 2009

Leviţchi 2006

M. Horváth 2002

Machortych 2017

Metzner-Nebelsick 2002

Miroššayová 2015

Miroššayová 2018

Mogilov 2008

Mogilov/Gucal/Gucal 2016

Mozsolics 1953

Müller 2012

Nebehay 1993

Parzinger/Nekvasil/Barth 1995

Patay 1961

Patay/B. Kiss 2001-2002

Párducz 1943
A. Kozubová: Dial'kové zbrane z pohrebísk vekerzugskej kultúry na juhozápadnom Slovensku. Zborník SNM 103. Archeológia 19, 2009, 65-130.

A. Kozubová: Súčasti konských postrojov z lokalít vekerzugskej kultúry na juhozápadnom Slovensku (čast’ I). Musaica 27, 2011, 69-100.

A. Kozubová: Vreckový nožík alebo britva? K interpretácii niektorých predmetov z kosti a parohoviny z pohrebísk vekerzugskej kultúry (na základe nálezov z chotínskych pohrebísk). Zborník SNM 106. Archeológia 22, 2012, 59-77.

A. Kozubová: Pohrebiská vekerzugskej kultúry v Chotíne na juhozápadnom Slovensku. Vyhodnotenie. Dissertationes Archaeologicae Bratislavenses 1. Bratislava 2013.

A. Kozubová: Pohrebiská vekerzugskej kultúry v Chotíne na juhozápadnom Slovensku. Katalóg. S dodatkom Pohrebisko vekerzugskej kultúry v Senci-Štrkovej kolónii. Dissertationes Archaeologicae Bratislavenses 1. Bratislava 2013.

A. Kozubová: „Something happened in the East but more in the West and South.“ Einige kritische Bemerkungen zu östlichen Einflüssen in der Vekerzug-Kultur. Musaica archaeologica 4, 2019, 55-185.

A. Kozubová: „Mutig wie ein Adler, schnell wie ein Pferd.“ Untersuchungen zu den Gräbern der Vekerzug-Kultur mit Waffen und Pferdegeschirr: Fallstudie. Musaica archaeologica 4, 2019, 27-109.

K. Kromer: Das Gräberfeld von Hallstatt. Firenze 1959.

I. N. Kulatova/L. N. Lugovaja/A. V. Suprunenko: Kurgany skifskogo vremeni meždureč́ ja Vorskly i Pskla. Moskva - Poltava 1993.

I. Kuzma: Multikulturelle Siedlung in Mužla-Čenkov. In: Gy. Kovács/G. Kulcsár (eds.): Ten Thousand Years along the Middle Danube. Life and Early Communities from Prehistory. Varia Archeologica Hungarica 26. Budapest 2011, 71-90.

A. Leszih: Borsodmegyei szkíta leletek. Folia Archaeologica 1-2, 1939, 68-87.

O. G. Levickij/M. T. Kašuba: O kulturnych tradicijach v pogrebal’noj obrjadnosti naselenija, proživavšego na zapadnych rubežach Archaičeskoj Skifii (istočniki, problematika). In: Epocha rannego železa. Sbornik naučnych trudov $k$ 60. letiju S. A. Skorogo. Kiev - Poltava 2009, 250-267.

O. Leviţchi: Necropola tumulară hallstattiană tarzie Trinca - «Drumul Feteştilor». Bibliotheca Archaeologica Moldaviae III. Iaşi 2006.

A. M. Horváth: Előzetes jelentés, a Bp. XVII. ker. Rákospalota - Újmajorban előkerült szkíta kori településrészletről. Budapest Régiségei 35, 2002, 103-123.

S. V. Machortych: Pronizi dlja perekrestnych remnej konskoj uprjaži na juge Vostočnoj Evropy v VII-VI vv. do n. e. Archeologija i davnja istorija Ukrajni 2/23, 2017, 166-184.

C. Metzner-Nebelsick: Der "Thrako-Kimmerische“ Formenkreis aus der Sicht der Urnenfelder- und Hallstattzeit im südöstlichen Pannonien. Vorgeschichtliche Forschungen 23. Rahden/Westf. 2002.

E. Miroššayová: Pohrebisko v Ždani v kontexte vývoja severného Potisia v dobe halštatskej. Archaeologica Slovaca Monographiae 24. Nitra 2015.

E. Miroššayová: Sídliskové objekty vekerzugskej kultúry v povodí Laborca. Východoslovenský pravek 11, 2018, 39-73.

O. D. Mogilov: Snorjadžennja konja skifskoj dobi v Lisostepu Schidnoj Evropi. Kijv Kam'janec' Podil'skij 2008.

O. D. Mogilov/A. F. Gucal/V. A. Gucal: Kurgan z kam'janim valom na Zachidnomu Podilli. Archeologija i davnja istorija Ukrajni 2/19, 2016, 212-230.

A. Mozsolics: Mors en bois de cerf sur le territoire du bassin des Carpathes. Acta Archaeologica Academiae Scientiarum Hungaricae 3, 1953, 69-109.

S. Müller: Smolenice-Molpír, Sered' und Ratkovce. Studien zu Siedlungen der frühen Eisenzeit in der Südwestslowakei. Universitätsforschungen zur prähistorischen Archäologie 220. Bonn 2012.

S. Nebehay: Latènegräber in Niederösterreich. Kleine Schriften aus dem Vorgeschichtlichen Seminar Marburg 41. Marburg 1993.

H. Parzinger/J. Nekvasil/F. E. Barth: Die Býčí skála-Höhle. Ein hallstattzeitlicher Höhlenopferplatz in Mähren. Römisch-Germanische Forschungen 54. Mainz 1995.

P. Patay: Az alsótelekesi vaskori temető. Folia Archaeologica 13, 1961, 27-50.

P: Patay/Sz. B. Kiss: Az alsótelekes-dolinkai szkítakori temető közöletken sírjai (az 1962. és 1964. évi feltárás eredményei). Folia Archaeologica 40, 2001-2002, 79-141.

M. Párducz: Szkítakori temető Békéscaba-Fényes. Archaeologia Értesitő 4, 1943, 50-63. 
Párducz 1954

Párducz 1955

Párducz 1965

Párducz 1966

Párducz 1969

Petrenko 1978

Podborský 1955

Polgár 2007

Polidovič 2004

Ramsl 2002

Romsauer/Hečková/Repka 2019

Scholtz 2006

Scholtz 2008

Scholtz 2010

Scholtz 2012

Stegmann-Rajtár 2009

Stöllner 2002

Szabó/Fekete 2014

Tankó 2015

Tecco Hvala 2012

Tecco Hvala/Dular/Kocuvan 2004

Tézer 2011

Točík 1987

Tugya 2010

Uzsoki 1987

Vaday 2000

Vinogradov 1972
M. Párducz: Le cimetière hallstattien de Szentes-Vekerzug II (Les fouilles de 1952 et 1953). Acta Archaeologica Academiae Scientiarum Hungaricae 4, 1954, 25-91.

M. Párducz: Le cimetière hallstattien de Szentes-Vekerzug III. Acta Archaeologica Academiae Scientiarum Hungaricae 6, 1955, 1-22.

M. Párducz: Graves from the Scythian Age at Ártánd (county Hajdú-Bihár). Acta Archaeologica Academiae Scientiarum Hungaricae 17, 1965, 137-231.

M. Párducz: The Scythian Age cemetery at Tápiószele. Acta Archaeologica Academiae Scientiarum Hungaricae 18, 1966, 35-91.

M. Párducz: Szkítakori leletek Heves megyében. Az Egri Múzeum Értesítője 7, 1969, 35-54.

V. G. Petrenko: Ukrašenija Skifii VII-III vv. do n. e. Svod archeologičeskich istočnikov D1-4. Moskva 1978.

B. Podborský: Skythsko-halštatské sídlištní nálezy na Slovensku. Archeologické rozhledy 7, 1955, 458-486.

Z. Polgár: Szkíta kori temető Abony határában. Előzetes jelentés. Tisicum 16, 2007, 313-326.

Ju. B. Polidovič: Zoomorfno oformlennye psalii kak fenomen skifskoj epochi. In: A. N. Usačuk (ed.): Psalii. Elementy uprjaži i konskogo snarjaženija v drevnosti. Archeologičeskij al'manach 15. Doneck 2004, 143-165.

P. C. Ramsl: Das eisenzeitliche Gräberfeld von Pottenbrunn. Horn 2002.

P. Romsauer/J. Hečková/D. Repka: Chotín VII. Sídlisko z doby halštatskej, rímskej a stredoveku. Nitra 2019.

R. Scholtz: Szkíta kori település- és temetőrészlet Tiszalök határában. Régészeti kutatások Magyarországon 2006, 2006, 53-65.

R. Scholtz: Szkíta, szarmata és késő népvándorlás kori leletek Tiszavasvári-Kapusz-lapos lelőhelyről. A nyíregyházi Jósa András Múzeum Évkönyve 50, 2008, 225-269.

R. Scholtz: New date on the Scythian Age Settlement History of Szabolcs Country. Hungary. In: S. Berecki (ed.): Iron Age Communities in the Carpathian Basin. Târgu Mureş 2010, 79-98.

R. Scholtz: Scythian Age Burials at Tiszalök. In: S. Berecki (ed.): Iron Age Rites and Rituals in the Carpathian Basin. Târgu Mureş 2012, 77-100.

S. Stegmann-Rajtár: Žiarové pohrebisko východohalštatskej a vekerzugskej kultúry v Nových Zámkoch. Príspevok k pohrebiskám doby halštatskej vo východoalpsko-zadunajskej oblasti. Slovenská archeológia 57, 2009, 57-116.

Th. Stöllner: Die Hallstattzeit und der Beginn der Laténezeit im Inn-Salzach-Raum. Auswertung. Archäologie in Salzburg 3. Salzburg 2002.

G. Szabó/M. Fekete: Pannon tumulus feltarasanak előkeszitese - Regoly, Strupka-Magyar birtok (4. februar-19. junius 2011). A Wosinsky Mór Múzeum Évkönyve 36, 2014, 7-157.

K. Tankó: Die skythischen Funde der Alföld Gruppe aus Kazár und Szurdokpüspöki (Ungarn). In: I. Szathmári (Hrsg.): An der Grenze der Bronze- und Eisenzeit. Festschrift für Tibor Kemenczei zum 75. Geburtstag. Budapest 2015, 431-443.

S. Tecco Hvala: Magdalenska gora. Dzužbena struktura in grobni rituali železnodobne skupnosti. Opera Instituti Archaeologici Sloveniae 26. Ljubljana 2012.

S. Tecco Hvala/J. Dular/E. Kocuvan: Železnodobne gomile na Magdalensko gori. Katalogi in monografije 36. Ljubljana 2004.

Z. Tézer: Szkíta kori településrészlet Budapest XV. kerület Rákospalota - Újmajorban lelőhelyéröl. Budapest Régiségei 44, 2011, 100-137.

A. Točík: Záchranný výskum v Lipovej-Ondrochove v roku 1980. Študijné zvesti Aú SAV 23, 1987, 243-275.

B. Tugya: Állatcsontleletek Ludányhalászi-Sóderbánya lelőhelyről. In: Sz. Guba/ K. Tankó (eds.): „Régről kell kezdenünk...” Studia Archaeologica in honorem Pauli Patay. Szécsény 2010, 353-365.

A. Uzsoki: Ménfőcsanak. In: T. Kovács/É. F. Petres/M. Szabó (eds.): Transdanubia 1. Corpus of Celtic Finds in Hungary I. Budapest 1987, 13-61.

A. Vaday 2000: Salgótarján, Ipari-park II. lelőhely. Régészeti kutatások Magyarországon 2000, 2000, 31-38.

V. B. Vinogradov: Central'nyj i Severo-Vostočnyj Kavkaz v skifskoe vremja. Groznyj 1972. 


\title{
Nech kosti prehovoria! Predmety z kosti, parohoviny a zvieracích zubov vo vekerzugskej kultúre
}

\author{
A nita Kozubová
}

Súhrn

Predložená štúdia sa zaoberá vyhodnotením predmetov z kostí, parohoviny a zvieracích zubov najmä z pohrebísk vekerzugskej kultúry (d’alej VK), nakol’ko ich sídliskové nálezy sú kvôli malému počtu kompletne publikovaných lokalít zatial' málopočetné. Z kosti a parohoviny sa vo VK zhotovovali najmä funkčne rozmanité duté valcovité predmety a obloženia rukovätí železných nožov. Ostatné typy predmetov ako zbrane a ich príslušenstvo, konský postroj, šperk a pracovné nástroje sa v nálezovom súbore vyskytli zriedkavo. Niektoré typy predmetov z kosti a parohoviny, ako napr. ozdobné súčasti tulcov na šípy, rôzne valcovité predmety, železné nože s organickým obložením rukoväte alebo dvojdielne britvy, slúžili vo VK spolu so zbraňami, konským postrojom a šperkom z kovu a d’alších materiálov $\mathrm{k}$ vizualizácii sociálnych identít. Aj napriek ich relatívne nízkej chronologickej vypovedacej hodnote dokladajú niektoré nálezy z kosti a parohoviny intenzívne kontakty VK so susednými kultúrnymi regiónmi.

V materiálnej náplni VK sú zastúpené také typy predmetov z kosti a parohoviny, ktoré sú územne ohraničené na oblast’ rozšírenia VK (valcovité súčasti jazdeckých bičíkov, železné pracovné a bojové nože s geometricky a zoomorfne zdobeným kosteným obložením rukoväte, zoomorfné ozdoby tulcov na šípy ako aj ich ozdoby v tvare kríža, niektoré zoomorfné motívy - hlavičky koní), alebo majú mnohé tažiská rozšírenia, konkrétne vo východohalštatskej kultúre (dvojdielne britvy, valcovité schránky na uchovávanie kozmetických prípravkov, niekoré typy ozdôb ohlávky, geometrické výzdobné motívy) alebo v lesostepnej zóne východnej Európy a na severnom Kaukaze (hroty šípov, bočnice zubadiel, niektoré typy ozdôb ohlávky, niektoré zoomorfné motívy hlavičky orlov). Podrobné vyhodnotenie artefaktov z kosti, parohoviny a zvieracích zubov zároveň potvrdzuje doterajšie výsledky analýzy materiálnej náplne, pohrebného rítu a zloženia hrobovej výbavy, krojov, sociálnej a sídliskovej štruktúry ako aj schém výzbroje VK. Jasne dokazuje, že v materiálnej náplni VK nie sú spolahlivo doložené žiadne nálezy z východoeurópskej stepnej oblasti, preto neexistujú žiadne dôvody označovat’ VK za kultúru skýtsku, skytoidnú či skýtsky ovplyvnenú. Ani celkový charakter východných vplyvov neumožňuje priradit VK k východným kultúram.

Obr. 1. Zbrane a ich príslušenstvo z kosti a parohoviny z lokalít vekerzugskej kultúry. 1-3 - Törökszentmiklós-Surján, kostrový hrob 31 (podla Kemenczei 1986, obr. 6: 11, 12; 7: 1); 4, 5 - Senec-Štrková kolónia, kostrový hrob 3/k (podla Kozubová 2013b, Taf. 122: 14); 6 - jaskyňa Szendrö (podla Kemenczei 1986, obr. 8: 2); 7 - Košice (podl’a Párducz 1965, obr. 9: 2). Rôzne mierky.

Obr. 2. Tiszalök-Börtön. Žiarový hrob 320 (podla Scholtz 2006, obr. 5). Mierka: a - 1-14; b - 15, 16.

Obr. 3. Bojové a pracovné nože so zdobeným obložením rukoväte z parohoviny a kosti z lokalít vekerzugskej kultúry. 1 - Szentes-Vekerzug, kostrový hrob 120 (podla Kemenczei 2009, tab. 77: 1); 2 - Csárdaszállás-Hanzélitanya, kostrový hrob 17 (podla Kemenczei 2009, tab. 16: 10); 3 - Vel'ký Grob, sídliskový objekt 2/82 (podla Kemenczei 2009, tab. 185: 11); 4 - Nyíregyháza-Mandabokor, sídliskový objekt 446 (podla Kemenczei 2009, tab. 54: 6, 7); 5 - Lajosmizse, sídliskový nález (podla Kemenczei 2009, tab. 30: 6); 6 - Mužla-Čenkov, sídliskový objekt 823 (podla Kuzma 2011, obr. 10: 2, 6); 7 - Chotín IA, kostrový hrob 13/52 (podla Kozubová 2013b, tab. 38: 14, 14a); 8 - Chotín IA, žiarový hrob 67/53 (podla Kozubová 2013b, tab. 19: 12, 12a, 12b). Rôzne mierky.

Obr. 4. Konský postroj z parohoviny a kosti z lokalít vekerzugskej kultúry. 1 - Pusztataskony-Ledence 1, sídliskový objekt 487 (podla F. Tot 2015, obr. 2); 2 - Sándorfalva-Eperjes, hrob 136 (podla Galántha 1985, obr. 7: 7a, 7b); 3-7 - Mátraszele, kostrový hrob (podla Kemenczei 1986, obr. 3); 8-24 - Cegléd-Hordógyár, kostrový hrob (podla Kemenczei 1986, obr. 4, 5). Rôzne mierky.

Obr. 5. Chotín IB. Kostrový hrob 46/61 (podla Kozubová 2013b, tab. 101). Mierka: a - 1; b - 2-6.

Obr. 6. Bátmonostor-Szurdok. Nálezy z hrobu (podla Gyucha u. a. 2015, obr. 2-5). Mierka: a - 1, 3-5, 10-17; b - 2, $6-9,18,19$.

Obr. 7. Mezőtúr-Újváros. Nálezy z hrobu (podl’a Kisfaludi 1983, obr. 1). Mierka: a -1-5, 7; b - 6 .

Obr. 8. Chotín IB. Kostrový hrob 49/61 (podl’a Kozubová 2013b, tab. 102). Mierka: a -1-3; b-4-12.

Obr. 9. Chotín IB. Kostrový hrob 49/61, pokračovanie (podla Kozubová 2013b, tab. 103).

Obr. 10. Chotín IA. Kostrový hrob 143/53 (podl’a Kozubová 2013b, tab. 55: 9-13). Mierka: a - 1-3, 5; b - 4. 
Obr. 11. Ozdoby z kosti/parohoviny a zvieracích zubov z lokalít vekerzugskej kultúry. 1-7 - Alsótelekes-Dolinka, žiarový hrob 110 (podla Patay/B. Kiss 2001-2002, obr. 8: 1-4, 6-8); 8-12 - Chotín IA, kostrový hrob 285/54 (podla Kozubová 2013b, tab. 88: 18-22); 13-18 - Csárdaszállás-Hanzélitanya, žiarový hrob 22 (podla Kemenczei 2001-2002, obr. 4: 18-23); 19-22 - Chotín IA, kostrový hrob 115/53 (podla Kozubová 2013b, tab. 49: 14-17). Rôzne mierky.

Übersetzung von Autor

Mgr. Anita Kozubová, PhD.

Archeologický ústav SAV

Akademická 2

SK - 94921 Nitra

anitakozub@gmail.com 